\title{
Green Approaches for Sustainable Development of Liquid Separation Membrane
}

\author{
Wei Jie Lee ${ }^{1}$, Pei Sean Goh ${ }^{1, *}$, Woei Jye Lau ${ }^{1}$, Ahmad Fauzi Ismail ${ }^{1}$ and Nidal Hilal ${ }^{2, *(\mathbb{D}}$ \\ 1 Advanced Membrane Technology Research Centre, School of Chemical \& Energy Engineering, Faculty of \\ Engineering, Universiti Teknologi Malaysia, Skudai 81310, Johore, Malaysia; weijie934@hotmail.com (W.J.L.); \\ wjlau@petroleum.utm.my (W.J.L.); afauzi@utm.my (A.F.I.) \\ 2 Water Research Centre, New York University Abu Dhabi (NYUAD), Saadiyat Marina District, \\ Abu Dhabi PO Box 129188, United Arab Emirates \\ * Correspondence: peisean@petroleum.utm.my (P.S.G.); nidal.hilal@nyu.edu (N.H.)
}

Citation: Lee, W.J.; Goh, P.S.; Lau, W.J.; Ismail, A.F.; Hilal, N. Green Approaches for Sustainable Development of Liquid Separation Membrane. Membranes 2021, 11, 235. https://doi.org/10.3390/

membranes 11040235

Academic Editor: Asuncion

Maria Hidalgo

Received: 27 February 2021

Accepted: 22 March 2021

Published: 25 March 2021

Publisher's Note: MDPI stays neutral with regard to jurisdictional claims in published maps and institutional affiliations.

Copyright: (c) 2021 by the authors. Licensee MDPI, Basel, Switzerland. This article is an open access article distributed under the terms and conditions of the Creative Commons Attribution (CC BY) license (https:// creativecommons.org/licenses/by/ $4.0 /)$.

\begin{abstract}
Water constitutes one of the basic necessities of life. Around 71\% of the Earth is covered by water, however, not all of it is readily available as fresh water for daily consumption. Fresh water scarcity is a chronic issue which poses a threat to all living things on Earth. Seawater, as a natural resource abundantly available all around the world, is a potential water source to fulfil the increasing water demand. Climate-independent seawater desalination has been touted as a crucial alternative to provide fresh water. While the membrane-based desalination process continues to dominate the global desalination market, the currently employed membrane fabrication materials and processes inevitably bring adverse impacts to the environment. This review aims to elucidate and provide a comprehensive outlook of the recent efforts based on greener approaches used for desalination membrane fabrication, which paves the way towards achieving sustainable and ecofriendly processes. Membrane fabrication using green chemistry effectively minimizes the generation of hazardous compounds during membrane preparation. The future trends and recommendations which could potentially be beneficial for researchers in this field are also highlighted.
\end{abstract}

Keywords: sustainable membrane desalination; environmental friendliness; green solvents; solvent free; click chemistry; chemical vapor deposition; plasma treatment

\section{Introduction}

As the demand for fresh water surges due to population and economic growth, the development of agricultural activities, industrialization and a decrease in available fresh water supply, desalination has become a promising technology to produce fresh water [1]. Desalination converts water with a high salt concentration, such as saline water, brine water, and brackish water, into fresh water. Over the last decade, desalination has become increasingly important around the world with significant growth in Asia and the Americas [2]. The majority of the installed desalination plants are located in the Middle East where seawater is plentiful and fresh water is scarce [3]. Desalination technologies can mainly be classified into thermal-based and membrane-based desalination [4-6]. While there are multiple ways to operate these desalination technologies, the systems being commercially employed are usually multi-stage flash (MSF), reverse osmosis (RO), and multi-effect distillation (MED) due to their high desalination efficiency $[7,8]$. Nonetheless, the preparation materials used and brine waste produced throughout the processes could impose adverse environmental pollution, making the whole process unsustainable and not environmentally friendly.

Membrane-based desalination processes are gaining worldwide attention due to their unparalleled advantage over their traditional counterparts. Membrane-based desalination are accounted for $60 \%$ of total desalination plants $[9,10]$. Compared to the traditional desalination technologies, membrane technologies are well recognized for its high selectivity, low 
carbon footprint, reduced energy expenditure, and minimized usage of auxiliary chemicals to carry out the process [11]. Among the membrane desalination technologies, RO and nanofiltration (NF) are classified as pressure-driven processes whereby hydraulic pressure is applied to overcome the osmotic pressure and thus effectively remove solutes from a highly concentrated feed solution (FS) [12]. These pressure-driven processes are also energy-intensive, whereby its power consumption could range from 2 to $5 \mathrm{~kW} \cdot \mathrm{h} \cdot \mathrm{m}^{-3}$ depending on the nature of FS $[13,14]$. Membrane distillation (MD) involves the vaporization of water at a temperature lower than the boiling point, whereby vapor is passed through a hydrophobic membrane retaining the liquid phase solutes at the feed side. The heating process is energy intensive and requires much more than that of RO and NF [15,16]. As the energy consumption which accounts for a significant portion of the total operating cost is the major bottleneck of desalination processes, various efforts are underway to address this limitation. For instance, installing an efficient pre-treatment system and energy recovery devices has remarkably reduced the energy expenses of the desalination process [17-19]. Various alternative desalination processes have also been explored for the same purpose. Forward osmosis (FO), which utilizes an osmotic pressure gradient as a driving force to separate pure water from FS using a more concentrated draw solution (DS), stands out as an emerging process for desalination. While a single unit of FO is impractical to obtain desalinated drinking water, FO has been feasibly coupled with RO, NF and/or MD as the pre-treatment process aiming to desalinate water at a lower energy cost [20-22].

The preparation of a polymeric membrane for desalination usually requires two steps, which are substrate preparation followed by the active layer coating atop the substrate. Either way, coating can sometimes be unnecessary, depending on the type of application. In the substrate preparation stage, several methods such as phase inversion, electrospinning, stretching and sintering are employed [23]. Phase inversion and electrospinning require solvents while the rest do not. This review focused on phase inversion or phase separation, as the most common and principal method for substrate preparation. During phase inversion, a substrate in the pore size range of ultrafiltration (UF) is produced [24-26]. To prepare a membrane with a finer pore size range for the application of $\mathrm{NF}, \mathrm{RO}$, and FO, a thin film composite (TFC) membrane is made with an active layer coated substrate. Meanwhile, the MD application fundamentally requires an asymmetric membrane which is usually modified with hydrophobic coating. To fabricate the TFC membrane, the active layer coating can be done in several means, with interfacial polymerization (IP) as the most common way. Meanwhile, for MD hydrophobic coating, there are methods such as low surface tension coating, and/or the employment of nanostructures to increase surface roughness [27].

Although membrane technologies in general have been acknowledged as eco-friendly technologies compared to other contemporary separation technologies, it is not always the case in membrane preparation. During the membrane preparation process, large amounts of toxic solvents such as $N$-methyl-2-pyrrolidone (NMP), N,N-dimethylacetamide (DMA), $N, N$-dimethylformamide (DMF) and tetrahydrofuran (THF) are often used [28]. These solvents pose potential risks related to hazardousness and toxicity towards health and the environment. The fabrication of polymeric membrane induces an environmental issue which limits operation in the long run. In light of increasingly severe environmental issues, the recent development of membrane desalination has been progressively transformed to achieve better sustainability. From the environmental point of view, a process is deemed sustainable if it does not cause severe pollution which might threaten lives. The preferred solution in achieving sustainability follows the sequence of reduction, reuse, recycling, treatment, and disposal. The former three options, reduce, reuse and recycle, or commonly known as the 3Rs, uphold the ideology of circular economy [29]. In most cases, reuse is a more favorable option compared to recycling as recycled resources would still go through another production stage whereby energy and materials are further expended. Ultimately, reducing is the most preferable approach as the reduced resources usage can save in terms of the efforts needed for all the other steps [30]. 
A thorny dilemma is that throughout the entire membrane preparation process, the use of solvents which are toxic to the environment is inevitable. A green membrane fabrication process promotes sustainability and prolongs the process. Applying green chemistry to membrane fabrication serves as a good way of reducing the use of resources, which complies with the concept of 3Rs. It potentially minimizes the amount of hazardous waste created to be disposed, recycled and reused. In this review, the application of green solvents and solvent-free methods for membrane preparation as some green alternatives for the assurance of environmental friendliness are discussed. Green solvents are those characterized by non-toxicity, low volatility, and/or derivatives of renewable sources. Complying with the Twelve Principles of Green Chemistry which state that conventional solvents should be replaced with low-toxicity, recyclable, inert, abundant, easily separable, green solvents, or be solventless, could then pave the way to pollution-free desalination as the world is facing water shortage challenges and naturally occurring resources like seawater are the best place to channel water sources [31].

Kim et al. [32] reviewed the recent progress in improving the sustainability of membrane fabrication using green solvents and chemicals. The recently identified green solvents with their novel procedures of employment for the fabrication of a high-performance membrane have been documented. Figoli et al. [24] reviewed the application of a wide range of solvents in membrane fabrication. Twelve green principles were provided to identify the toxicity level of solvents, and also to identify whether a novel solvent is deemed a green solvent that does not adversely impact the environment.

Despite all the previous efforts, a comprehensive review covering the complete membrane preparation process, from substrate fabrication to membrane modification and post-treatment using a greener approach, is still lacking. This paper provides a comprehensive review which involves all of them, granting a better understanding and insight to readers as a whole. In addition, the literature summarized in their studies mainly comprises dye and protein rejections as applications below the NF range. In this review, the scope is focused on membrane production for application related to desalination application (NF to FO range). This review serves as a foundation for future studies, giving readers valuable literature and a more updated knowledge for understanding the current trend in sustainable ways of membrane preparation, in turn inspiring some new ideas and creating new insights for more innovations. In this contribution, the discussion was conducted in a progressive manner, whereby the substrate preparation stage using green solvents was discussed first, followed by solvent-free methods for membrane modification. Finally, the review concludes with future challenges on several prospects and concise conclusions.

\section{Substrate Preparation via Phase Inversion}

Ideally, substrate preparation without solvents would be the most perfect way to promote environmental cleanliness. Nonetheless, for decades, the majority of membranes are prepared through solution-based process, mainly phase inversion. Switching the solution-based process to a non-solvent method would not enable maintaining the surface area production on par, at least for the current state. There is, however, a method such as $3 \mathrm{D}$ printing for micro and nanofabrications of UF and ceramic membranes, with the limitation of poor resolution which is to date unable to be scaled up to be commercially practical $[33,34]$. Three components are typically involved during phase inversion, namely the solvent, non-solvent, and polymers. The process, in brief, follows the sequence of the dissolution of polymers in the solvent, followed by casting on a support, and then immersion in a non-solvent coagulation bath. Phase inversion occurs as a result of the phase change of the dope solution or casting solution, comprising a homogeneously dissolved polymer in a solvent, which gives rise to polymer-poor and polymer-rich phases during the solidification process. Polymer-poor phases will form pores while polymerrich phases will become the support frame of the membrane [35]. The phase separation relies on the presence of a miscibility gap in the phase diagram [36]. The solution is unstable in the miscibility gap, hence liquid-liquid separation easily occurs forming a 
membrane structure (derived from polymer-rich phase) with pores (derived from the polymer-poor phase). Phase inversion can be generally classified into several types, such as temperature-induced phase separation (TIPS), non-solvent induced phase separation (NIPS), evaporation-induced phase inversion (EIPS), and vapor-induced phase inversion (VIPS) [37]. Among them, TIPS and NIPS are among the most popular substrate fabrication techniques for membrane-based desalination, which will be the focus the of this study [24].

In TIPS, the polymer is dissolved in a solvent commonly known as a latent solvent which only works at a high temperature close to the melting point of a polymer, forming a homogeneous solution [38,39]. The homogeneous dope solution is then immersed in a water bath and the decrease in temperature yields polymer precipitation. Depending on the temperature required, the whole process can be more energy intensive than NIPS. However, it is very effective in fabricating polymeric membranes with various morphologies $[36,40]$. By manipulating the temperature, the pore size of the membrane can be controlled significantly and hence the membrane with less defect formation, macrovoid absence, high mechanical strength, as well as isotropic and anisotropic structures, are possible to be prepared [41-44]. In NIPS, the polymer is allowed to dissolve in the solvent via stirring until a homogeneous dope solution is formed. It is then casted on a glass plate (flat sheet) or extruded through a spinneret (hollow fiber) followed by immersion in a non-solvent water bath. The exchange of a solvent allows the polymer precipitation forming membrane. The solvents used in NIPS can generally dissolve the polymer at room temperature $[45,46]$. Macrovoids and finger-like structures are formed within the membrane due to solvent/non-solvent exchange, resulting in weak mechanical strength. The membrane can rupture easily when working in a long-term process under high temperature. Figure 1 schematically illustrates the membrane fabrication through NIPS and TIPS with their respective membrane morphologies.

(a) Nonsolvent Induced Phase Separation (NIPS)

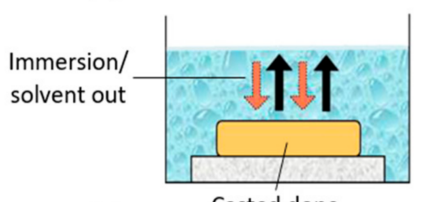

(b) Thermally Induced Phase Separation (TIPS)

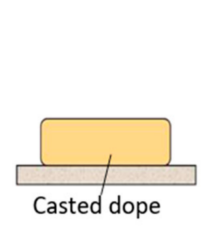

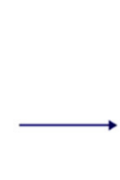

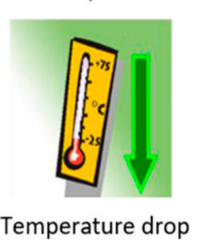

(c)

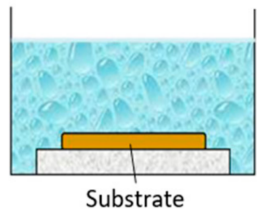

Substrate

(d)
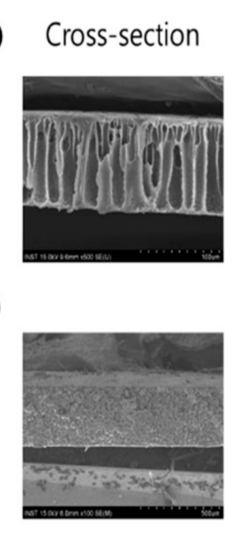

Top Surface
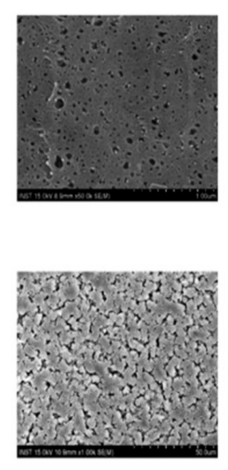

Figure 1. Phase inversion using: (a) NIPS; (b) TIPS with their respective (c); (d) cross-section and top surface morphologies [32].

\subsection{Green Solvents as Alternatives forTraditional Solvents}

It is worth noting that a lot of the commercial organic solvents used in polymer dissolution are toxic and harmful to the environment. For instance, the solvents traditionally employed for NIPS include NMP, DMA, DMF, THF, and 1,4-dioxane [47], while for TIPS these are methyl salicylate [48], phthalates [49,50], and diphenyl ether [51,52]. Table 1 shows the hazard classification of the toxic solvents commonly used for membrane preparation. Upon disposal into environment, these pose a dangerous risk to humans. At the industrial level, $95 \%$ of the total waste generated during membrane fabrication is accounted for by the wastewater contamination of these solvents [53]. It is eloquently stated that the amount of solvent used in a process can affect the magnitude of the health impact on humans [54]. Hence, lots of companies have taken the recycling of wastewater containing solvent into consideration by adopting methods such as adsorption or membrane separation [55]. Nonetheless, whilst solvent recycling is highly desirable, it is not always 
possible due to the quality requirement such as high purity and regulatory demand [56,57]. Many very large scale processes (bulk chemical synthesis) which involve solvents require "disposal solvents" that can be incinerated after being used, such as toluene.

Table 1. Hazard classification of the solvents commonly used for substrate fabrication [24].

\begin{tabular}{llll}
\hline Solvent & $\begin{array}{l}\text { Boiling } \\
\text { Point }\left({ }^{\circ} \mathbf{C}\right)\end{array}$ & $\begin{array}{l}\text { Fabrication } \\
\text { Method }\end{array}$ & Hazard and Toxicological Statements \\
\hline & & - Flammable liquid and vapor. \\
$\begin{array}{l}\text { Dimethylformamide } \\
(\mathrm{DMF})\end{array}$ & 153 & NIPS & $\begin{array}{l}\text { Harmful in contact with skin or if inhaled. } \\
\text { - Causes severe eye irritation. }\end{array}$ \\
& & - $\begin{array}{l}\text { Damages the unborn child. } \\
\text { Causes mutations in germ cells and mammalian somatic cells. }\end{array}$
\end{tabular}

- Harmful in contact with skin or if inhaled.

Dimethylacetamide (DMA) 166 NIPS $N$-methyl-2-pyrrolidone (NMP)
- Causes serious eye irritation.

- May damage the unborn child.

- Causes congenital malformation to the fetus.

- $\quad$ Produces human reproductive toxicant and causes reproductive disorders.
- Causes skin irritation.

- Causes serious eye irritation.

- Cause respiratory irritation.

- May damage the unborn child.

- $\quad$ May damage the fetus.

- Highly flammable liquid and vapor.

- Causes serious eye irritation.

- May cause respiratory irritation.

- $\quad$ Suspected of causing cancer.

- Forms explosive peroxides.

- $\quad$ May cause skin dryness or cracking.

- $\quad$ May damage the unborn child.

- $\quad$ Extremely toxic to aquatic life.

- Cause infertility.

- May damage the unborn child.

- Causes congenital malformation in the fetus.

- Produces human reproductive toxicant and causes reproductive disorders.
Acetone

56

NIPS
- Highly flammable liquid and vapor.

- Causes serious eye irritation.

- $\quad$ May cause drowsiness or dizziness. 
Table 1. Cont.

\begin{tabular}{|c|c|c|c|}
\hline Solvent & $\begin{array}{l}\text { Boiling } \\
\text { Point }\left({ }^{\circ} \mathrm{C}\right)\end{array}$ & $\begin{array}{l}\text { Fabrication } \\
\text { Method }\end{array}$ & Hazard and Toxicological Statements \\
\hline Chloroform & 61.2 & NIPS & $\begin{array}{l}\text { - } \quad \text { Harmful if swallowed or if inhaled. } \\
\text { - } \quad \text { Causes skin irritation effect. } \\
\text { - } \quad \text { Causes serious eye irritation. } \\
\text { - } \quad \text { Suspected of causing cancer. } \\
\text { - } \quad \text { Suspected of damaging the unborn child. } \\
\text { - } \quad \text { Causes germ cell mutation. } \\
\text { - } \text { May cause damage to organs through prolonged or } \\
\text { repeated exposure. }\end{array}$ \\
\hline Tetrahydrofuran (THF) & 66 & NIPS & $\begin{array}{l}\text { - } \quad \text { Highly flammable liquid and vapor. } \\
\text { - } \quad \text { Mauses serious eye irritation. } \\
\text { - } \quad \text { May lead to cancer. }\end{array}$ \\
\hline Toluene & 111 & NIPS & $\begin{array}{l}\text { - } \quad \text { Highly flammable liquid and vapor. } \\
\text { - } \quad \text { May be fatal if swallowed and enters airways. } \\
\text { - } \quad \text { May cause drowsiness or dizziness. } \\
\text { - } \quad \text { May damage fetus. } \\
\text { - } \text { May cause damage to organs through prolonged or } \\
\text { - Brings reproductive toxicity to male and female animals. }\end{array}$ \\
\hline
\end{tabular}

The growing awareness of the adverse impacts of toxic solvents has encouraged the use of non-toxic solvents as green alternatives to improve the sustainability of membrane preparation. An ongoing challenge emerges while replacing traditional solvents with green solvents. Water would make the greenest choice of solvent when it comes to availability and non-toxicity. Though it could be an interesting concept with huge potential, its practicability is rather restricted. Kamp et al. [58] utilized pure water as the solvent to induce phase separation and found out that phase separation and membrane formation depend solely on a change in $\mathrm{pH}$ as the driving force. Moreover, the process itself is unstable, and the membrane did not yield satisfactory performance. The green solvents selected in this study are not merely involved in the dissolution of the polymers, but must also serve the purpose of creating a membrane with desired performance and morphologies. During the membrane formation process, it is important to take note that solvent characteristics such as boiling point, dielectric constant, polarity, and viscosity could significantly affect the membrane characteristics.

Green solvents which are either chemically produced or naturally occurring have been discovered to be the promising candidates. For NIPS, dimethyl sulfoxide (DMSO), methyl lactate, ethyl lactate, and ionic liquids are some good non-toxic solvents to replace traditional ones; while for TIPS, acetyltributylcitrate (ATBC), acetyltriethylcitrate (ATEC), triacetin and soybean oil are some good alternatives. In this study, all the green solvents were categorized into synthetic organic solvents, bio-sourced solvents, and ionic liquids regardless of their fabrication technique. As solvents have different physicochemical properties that tend to interact with the polymer and the fillers leading to various membrane morphologies and properties, it is crucial to determine whether solvent replacement is able to maintain or achieve a better membrane performance instead of merely following the sustainable development agenda. Generally, a green solvent must be in compliance with a few principles of green chemistry, which are: (i) Safer solvents and auxiliaries: The use of auxiliary substances (e.g., solvents, separation agents) should be made unnecessary wherever possible and innocuous when used; (ii) Use of renewable feedstocks: A raw 
material or feedstock should be renewable rather than depleting whenever technically and economically practicable; (iii) Inherently safer chemistry for accident prevention: Substances and the form of a substance used in a chemical process should be chosen to minimize the potential for chemical accidents, including releases, explosions, and fires [59]. As most of the solvents used in membrane preparation are water insoluble, it is important to prepare an organic extraction bath to remove the excess solvents from the membrane. Despite the manifold advantages, in membrane desalination, the use of these green solvents is still scarce. Instead, they usually lead to preparing membranes for protein, sugar, or dye removal at the current state:

To execute solvent-based phase inversion perfectly, the prerequisite would be the complete dissolution of polymer. The affinity between polymer and solvent is hence an important factor that determines the phase separation process and the resulting membrane performance. It is critical to choose green solvent with good affinity towards the polymer to ensure proper dissolution. Ra value which is calculated by the Hansen solubility parameter (HSP) using the equation below can be used to describe such affinity:

$$
\mathrm{R}_{\mathrm{a}}=\sqrt{4\left(\delta_{1}-\delta_{\mathrm{d} 2}\right)^{2}+\left(\delta_{\mathrm{p} 1}-\delta_{\mathrm{p} 2}\right)^{2}+\left(\delta_{\mathrm{h} 1}-\delta_{\mathrm{h} 2}\right)^{2}}
$$

whereby $\delta_{\mathrm{d}}$ is the dispersion parameter, $\delta_{\mathrm{p}}$ is the polar parameter, and $\delta_{\mathrm{h}}$ is the hydrogen bonding parameter. The lower the $\mathrm{R}_{\mathrm{a}}$ value, the better the polymer-solvent compatibility, and the polymer will most probably be soluble in that solvent, as depicted in Figure 2. $R_{0}$ value can be used to indicate the Hansen solubility sphere of a polymer. In order to have good affinity towards a polymer, the $R_{a}$ value of a solvent must be smaller than $R_{0}$. Table 2 and Figure 3 further summarize the HSP values of some green solvents and typical polymers used in substrate fabrication. Red dots represent that $R_{a}<R_{0}$ (inside sphere), while green dots represent that $R_{0}<R_{a}$ (outside sphere).

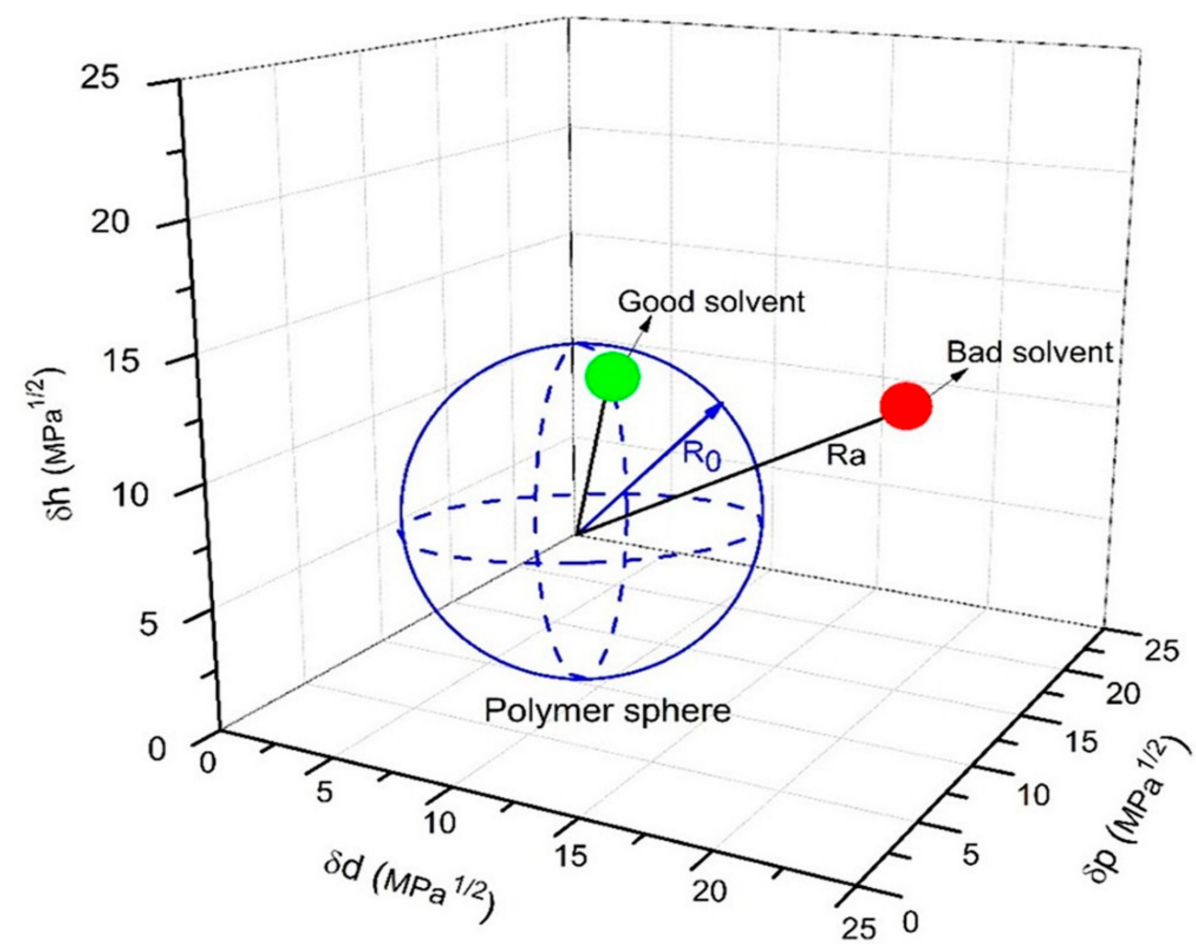

Figure 2. Interaction radius of the Hansen solubility sphere $\left(\mathrm{R}_{0}\right)$ for the radius determination of the good and bad solvents [60]. 
Table 2. HSP values of the polymers and the solvents, and the radius of interaction of the Hansen solubility sphere $\left(\mathrm{R}_{0}\right)$.

\begin{tabular}{|c|c|c|c|c|c|}
\hline Polymers & $\begin{array}{c}\delta_{\mathrm{d}} \\
\left(\mathrm{MPa}^{1 / 2}\right)\end{array}$ & $\begin{array}{c}\delta_{\mathrm{p}} \\
\left(\mathrm{MPa}^{1 / 2}\right)\end{array}$ & $\begin{array}{c}\delta_{\mathrm{h}} \\
\left(\mathrm{MPa}^{1 / 2}\right)\end{array}$ & $\begin{array}{c}\mathbf{R}_{0} \\
\left(\mathrm{MPa}^{1 / 2}\right)\end{array}$ & Ref. \\
\hline Cellulose acetate (CA) & 18.6 & 12.7 & 11 & 8.8 & [62] \\
\hline Polyvinylidene fluoride (PVDF) & 17.2 & 12.5 & 9.2 & 5 & [63] \\
\hline Polysulfone (PSU) & 19.7 & 8.3 & 8.3 & 8 & [62] \\
\hline Polyvinyl chloride (PVC) & 17.6 & 7.8 & 3.4 & 8.2 & [62] \\
\hline Polyacrylonitrile (PAN) & 21.7 & 14.1 & 9.1 & 10.9 & [62] \\
\hline Chitosan & 21.9 & 32.5 & 24.6 & NA & [60] \\
\hline \multicolumn{6}{|l|}{ Solvents } \\
\hline Acetyltributylcitrate (ATBC) & 16.02 & 2.56 & 8.55 & - & [64] \\
\hline Acetyltriethylcitrate (ATEC) & 16.6 & 3.5 & 8.6 & - & [65] \\
\hline Triethyl citrate (TEC) & 16.5 & 4.9 & 12 & - & [65] \\
\hline $\begin{array}{l}\text { Triethylene glycol diacetate } \\
\text { (TEGDA) }\end{array}$ & 16.45 & 2.14 & 9.78 & - & [66] \\
\hline Cyrene & 18.8 & 10.6 & 6.9 & - & [67] \\
\hline Dimethyl isosorbide (DMI) & 17.6 & 7.1 & 7.5 & - & [53] \\
\hline TamiSolve NxG & 17.8 & 8.2 & 5.9 & - & [68] \\
\hline Ethyl lactate & 16 & 7.6 & 12.5 & - & [62] \\
\hline Methyl lactate & 15.8 & 6.5 & 10.2 & - & [69] \\
\hline PolarClean & 15.8 & 10.7 & 9.2 & - & [63] \\
\hline Dimethylsulfoxide (DMSO) & 18.4 & 16.4 & 10.2 & - & [70] \\
\hline Triethylphosphate (TEP) & 16.8 & 11.5 & 9.2 & - & [71] \\
\hline$\gamma$-butyrolactone & 19 & 16.6 & 7.4 & - & [64] \\
\hline Propylene carbonate (PC) & 20 & 18 & 4.1 & - & [60] \\
\hline
\end{tabular}
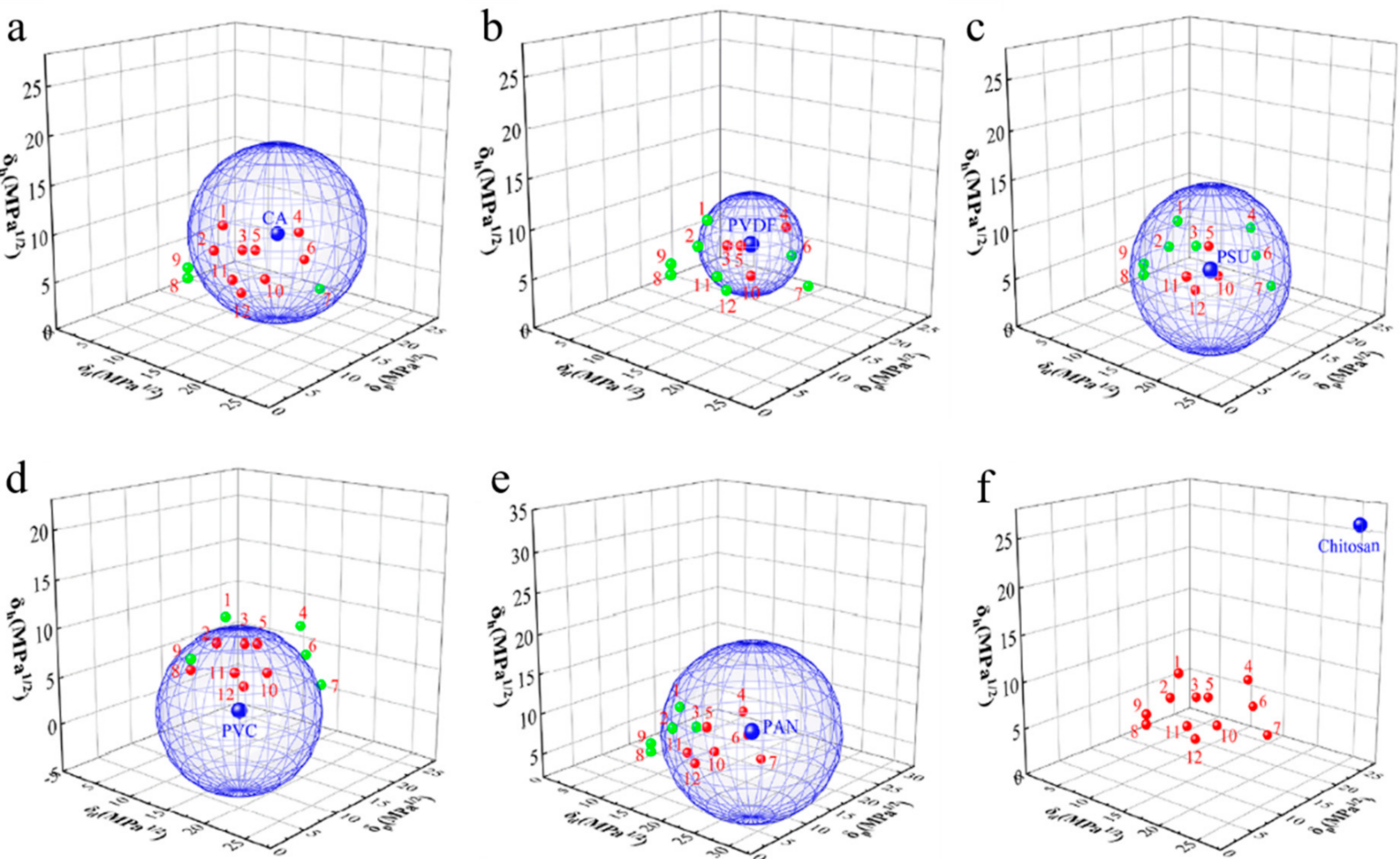

\begin{tabular}{|l|l|l|l|l|l|}
\hline 1: Ethyl lactate & 2: Methyl lactate & 3: PolarClean & $4:$ DMSO & 5: TEP & $6: \gamma$-butyrolactone \\
\hline 7: PC & 8: ATBC & 9: TEGDA & 10: Cyrene & 11: DMI & 12: TamiSolve NxG \\
\hline
\end{tabular}

Figure 3. 3D Hansen solubility parameter (HSP) spheres of green solvents and typical polymers (red dots indicate the inside sphere, green dots indicate the outside sphere) [61]. 


\subsection{Synthetic Organic Solvents}

\subsubsection{DMSO}

Highly volatile organic compound (VOC) solvents could emit toxic vapor harmful to the environment. DMSO as a low VOC solvent owing to its high boiling point $\left(189^{\circ} \mathrm{C}\right.$ at $1 \mathrm{~atm})$ and low vapor pressure $\left(0.6 \mathrm{mmHg}\right.$ at $\left.25^{\circ} \mathrm{C}\right)$ has low toxicity. It also has a very similar polarity and solvency power to NMP, DMF, and DMAC, which can effectively dissolve many types of polymers such as polysulfone (PSU) and polyvinylidene fluoride (PVDF), making it a good candidate for toxic solvent replacement [70]. In some studies, DMSO was reported to be a green, highly polar and water miscible organic solvent which does not have a harmful impact on the environment [24,72]. DMSO is made of lignin, a natural compound from tree cells which acts as glue giving to their mechanical structure. DMSO has the unique feature of being able to be quickly absorbed by human tissues, hence possessing the risk of carrying toxin on the skin. Nonetheless, if the solvent choice is mainly made in function of peculiar toxicity for human health, DMSO appears as a good replacement for more toxic solvents according to the principle of green chemistry stating "Safer solvents and auxiliaries: The use of auxiliary substances (e.g., solvents, separation agents, etc.) should be made unnecessary wherever possible and innocuous when used" [24]. The only shortcoming is its unpleasant odor, however, it has been significantly improved in the new version of DMSO EVOL ${ }^{\mathrm{TM}}$ [73].

Apart from lower toxicity, it is also important to determine to what extent solvent change can affect the performance of the membrane. Prihatiningtyas et al. [74] compared the membrane desalination performance of DMSO to several traditional solvents which are NMP, DMF and dioxane. Cellulose nanocrystals (CNCs)-incorporated cellulose triacetate (CTA) membranes were successfully fabricated via dope casting in different solvents. Among all the solvents, the DMSO-based membrane successfully outshined with a homogeneous distribution of $\mathrm{CNCs}$ on the membrane surface and decent performance. CNCs are a polar nanomaterial with surface charges and electrostatic repulsion interactions between the CNCs rods. Hence, compared to the other solvents, the strong polarity of $\operatorname{DMSO}(\delta \mathrm{p}=16.4 \mathrm{MPa} 1 / 2)$ potentially donates a strong ionic strength in the suspension, of which the resulting repulsion hinders CNC aggregation and is attributed to the homogeneous dispersion of CNCs. Consistent results can be observed from Figure 4a, in which the only dope solution with DMSO solvent yields a clear solution, indicating the homogeneous distribution of $\mathrm{CNCs}$, while the rest result in a rather cloudy solution. The resulting membranes (Figure 4c) prepared from four solvents also showed a similar outcome, with DMSO-based nanocomposite membrane having a transparent appearance while the other showing an opaque display. Meanwhile, Figure $4 \mathrm{~b}$ indicates that the surface of the DMSO-based nanocomposite membrane was the smoothest among all membranes due to the homogeneous distribution of CNCs, making water diffusion much easier with lower fouling propensity. The membrane provided decent water flux $\left(11 \mathrm{~kg} \cdot \mathrm{m}^{-2} \cdot \mathrm{h}^{-1}\right)$ without sacrificing the $\mathrm{NaCl}$ rejection (99.9\%) using $30 \mathrm{~g} \cdot \mathrm{L}^{-1}$ of $\mathrm{NaCl}$ solution as FS. Meanwhile, for a high $\mathrm{FS}$ concentration $\left(90 \mathrm{~g} \cdot \mathrm{L}^{-1}\right.$ of $\left.\mathrm{NaCl}\right)$, the NMP-based and dioxane-based membranes suffered from salt rejection and membrane leakage.

After that, the same group of researchers [75] incorporated alumina $\left(\mathrm{Al}_{2} \mathrm{O}_{3}\right)$ into CTA membranes also using DMSO as the solvent. It was then determined that alumina has excellent dispersibility in DMSO regardless of its concentration, with $2 \mathrm{wt} . \%$ alumina as the optimum concentration significantly improving the membrane hydrophilicity, thermal stability and mechanical strength. The resulting membrane outperformed the pristine CTA membrane with a promising flux enhancement of $204 \%$ using $30 \mathrm{~g} \cdot \mathrm{L}^{-1}$ as FS. Meanwhile, a decent salt rejection of more than $99.8 \%$ was obtained. Li et al. [76] fabricated polyamide (PA)/Kevlar aramid nanofiber (ANF) composite membranes for NF desalination. It is worth noting that ANF is a solvent-resistant Kevlar nanofiber. DMSO was again a great solvent able to homogeneously dissolve ANF forming ANF hydrogel dope, and then further fabricated into membrane via NIPS. The facile solvent treatment successfully shifted the desalination performance of the ANF-TFC membrane from RO into NF, which is one 
order of magnitude higher than the pristine TFC membrane. In terms of membrane characterization and performance, the ANF-TFC membrane exhibited lower surface roughness, lower surface zeta potential and higher surface hydrophilicity. Meanwhile, the salt-water separation performance was outstanding as well, with high rejections for monovalent salt ( $\mathrm{NaCl}, 80.3 \%)$ and multivalent salts $\left(\mathrm{MgSO}_{4}, 99.4 \% ; \mathrm{Na}_{2} \mathrm{SO}_{4}, 100 \% ; \mathrm{MgCl}_{2}, 92.7 \%\right.$ ). More interestingly, the performance WAs on par with the reference commercial NF membranes (NF270 and NF90) tested in cross-flow filtration.

(a)

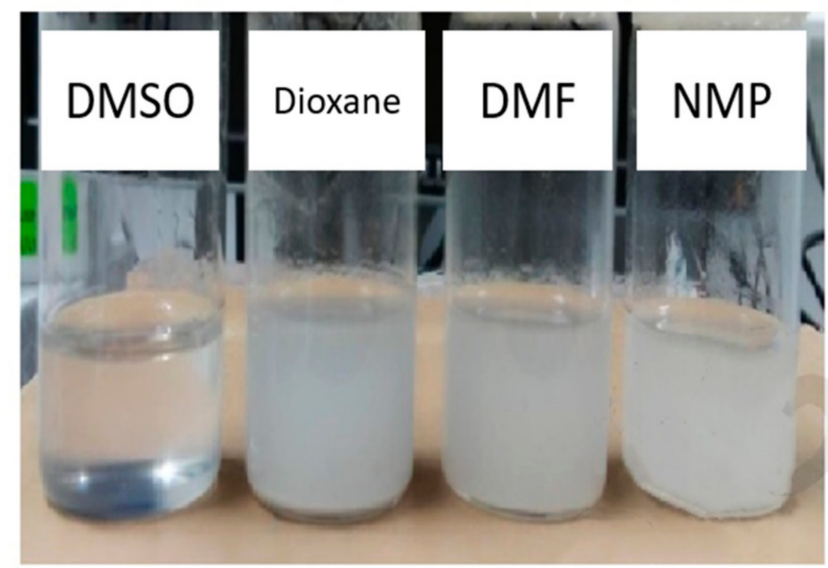

(b)
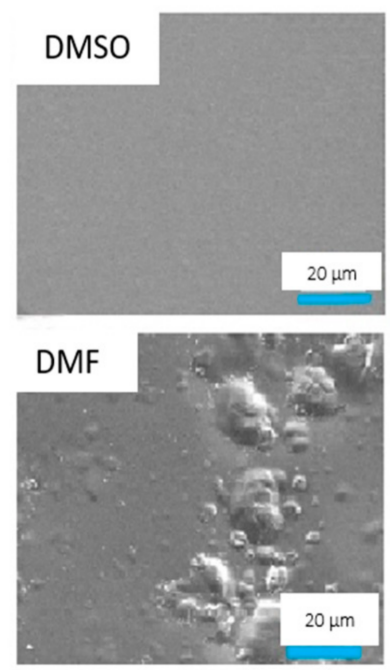
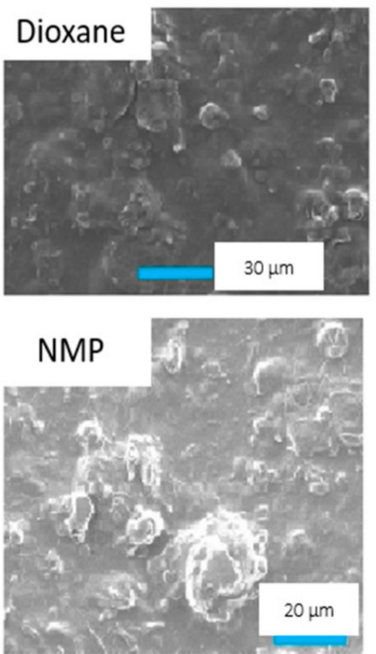

(c)
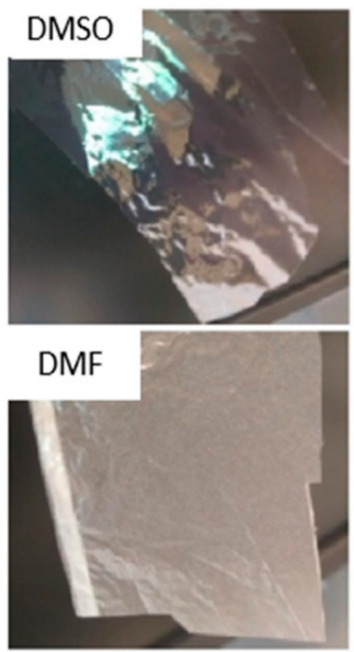
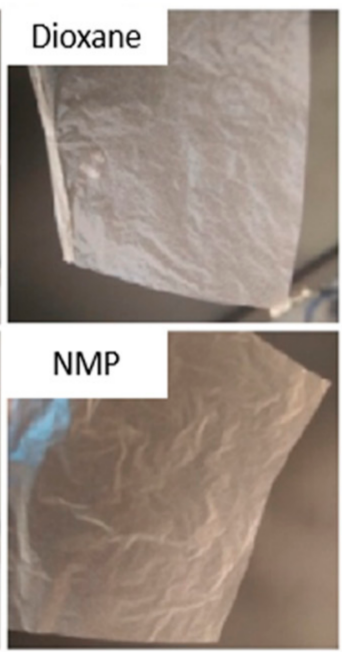

Figure 4. Labelled diagrams of: (a) Cellulose nanocrystals (CNCs) suspension in different solvents; (b) SEM images of nanocomposite membranes formed from different solvents; and (c) photographs of nanocomposite membranes formed from different solvents [74].

Wang et al. [77] investigated the effects of different solvents such as DMSO, TEP, DMA, DMF, and mixtures of them on the physicochemical properties of the fabricated membranes. The obtained results indicated that the skin layer formation on the surface of membrane was mainly affected by the equilibrium thermodynamics, while the solvent/nonsolvent exchange rate affected the support layer formation. It was reported that using DMSO which has a high polarity value as the solvent, the surface zeta potential of the membrane was more negative than the membranes fabricated using other solvents. The membrane fabricated using a mixture of TEP-DMSO solvent yielded the highest water permeability, followed by a membrane prepared using pure DMSO, accounting for the improved membrane surface negativity. Moreover, the membranes fabricated using DMSO as solvent had a higher porosity with more macrovoids and cellular pores in their structure. Adam et al. [78] and Sener et al. [79] both reported that membrane preparation using DMSO as solvents yielded a thinner active surface layer in comparison to other solvents like DMF 
and NMP. Hence, in terms of water selectivity and permeability, better performance was obtained. In a nutshell, DMSO has proven itself a promising alternative to replace the traditional toxic solvents for greener membrane fabrication.

\subsubsection{Dimethyl Carbonate}

Dimethyl carbonate (DMC) was another green solvent used by Shi et al. [80] as a cosolvent joint to tannic acid to fabricate the PSU-TFC membrane for RO desalination. DMC is environmentally benign as the building blocks mainly comprise of $\mathrm{CO}_{2}$, which does not emit VOCs to the atmosphere. It was observed that the addition of DMC co-solvent pronouncedly improved the leaf-like structure of the membrane surface which is favorable for solute rejection. The resulting membrane showed outstanding performance obtaining a water flux of $64.2 \mathrm{~L} \cdot \mathrm{m}^{-2} \cdot \mathrm{h}^{-1}$ and salt rejection of $99.03 \%$.

\subsubsection{TamiSolve NxG}

Marino et al. [68] first attempted to use TamiSolve NxG as a green solvent for poly(vinylidene fluoride-hexafluoropropylene) (PVDF-HFP) membrane preparation. Unlike NMP or DMA, TamiSolve NxG is not classified as a developmental-reprotoxic, which does not cause infertility and developmental toxicity in the offspring. Meanwhile, it has high chemical and thermal stability, as well as solvency similar to NMP and DMA towards a wide range of compounds making it a superb choice as a green solvent. The strong solvency of TamiSolve NxG can be further observed from the membrane characterization results, whereby thin membrane $(0.109 \mathrm{~mm})$ with small average pore size $(\sim 0.04 \mu \mathrm{m})$ was formed. Compared to the commercial polypropylene (PP) membrane, the resulting membrane exhibited a similar pore size. More importantly, when it was tested under direct contact membrane distillation (DCMD) desalination, satisfying water flux and rejection performance were obtained. The water flux increased gradually along the temperature, hitting a maximum flux of $\sim 25 \mathrm{~L} \cdot \mathrm{m}^{-2} \cdot \mathrm{h}^{-1}$ at $60{ }^{\circ} \mathrm{C}$. A consistent salt rejection of $99.5 \%$ was also obtained for three consecutive tests. Table 3 summarizes some previous works from several authors using synthetic organic solvents in membrane fabrication.

Table 3. Characteristics of synthetic organic solvents and their summarized studies in membrane desalination.

\begin{tabular}{|c|c|c|c|c|c|c|}
\hline Solvents & \multicolumn{2}{|c|}{ Chemical Structure } & $\begin{array}{l}\text { Boiling Point } \\
\left({ }^{\circ} \mathrm{C}\right)\end{array}$ & \multicolumn{3}{|c|}{ Green Credentials } \\
\hline $\begin{array}{c}\text { DMSO } \\
\left(\left(\mathrm{CH}_{3}\right)_{2} \mathrm{SO}\right)\end{array}$ & & & 189 & $\begin{array}{ll}\text { - } & \text { High bo } \\
\text { - } & \text { Low var } \\
\text { - } & \text { Water } \mathrm{m}\end{array}$ & $\begin{array}{l}\text { point } \\
\text { ressure } \\
\text { le }\end{array}$ & \\
\hline $\begin{array}{l}\text { Membrane } \\
\text { (Technology) }\end{array}$ & $\begin{array}{l}\text { Fabrication } \\
\text { Technique }\end{array}$ & Solvents & $\begin{array}{l}\text { Feed Conc. } \\
\left(\mathrm{g} \cdot \mathrm{L}^{-1}\right)\end{array}$ & $\begin{array}{l}\text { Water flux } \\
\left(\mathrm{L} \cdot \mathrm{m}^{-2} \cdot \mathrm{h}^{-1}\right)\end{array}$ & Salt rejection (\%) & Ref. \\
\hline $\begin{array}{l}\text { CTA/CNCs } \\
(\mathrm{PV})\end{array}$ & NIPS & $\begin{array}{l}\text { DMSO } \\
\text { Dioxane } \\
\text { NMP } \\
\text { DMF }\end{array}$ & 30.0 and 90.0 & $\begin{array}{l}11.67 \\
11.99 \\
11.68 \\
8.08\end{array}$ & $\begin{array}{l}\text { All > 99.0 } \\
\left(30.0 \mathrm{~g} \cdot \mathrm{L}^{-1} \mathrm{NaCl}\right) \\
\mathrm{DMSO}>99.0(90.0 \\
\left.\mathrm{g} \cdot \mathrm{L}^{-1} \mathrm{NaCl}\right)\end{array}$ & [74] \\
\hline $\mathrm{CTA} / \mathrm{Al}_{2} \mathrm{O}_{3}(\mathrm{PV})$ & NIPS & DMSO & 30.0 & 6.70 & $99.8(\mathrm{NaCl})$ & [75] \\
\hline ANF-PA (NF) & NIPS & DMSO & 1.0 & 57.60 & $\begin{array}{l}100.0\left(\mathrm{Na}_{2} \mathrm{SO}_{4}\right) \\
99.4\left(\mathrm{MgSO}_{4}\right) \\
92.7\left(\mathrm{MgCl}_{2}\right) \\
80.3(\mathrm{NaCl})\end{array}$ & [76] \\
\hline PAN/Zeolite $13 \times(\mathrm{PV})$ & NIPS & $\begin{array}{l}\text { DMSO } \\
\text { DMF } \\
\text { DMA }\end{array}$ & $\sim 50$ wt. $\%$ & $\begin{array}{l}27.70 \\
61.14 \\
3.45\end{array}$ & Highest (DMSO) & [79] \\
\hline
\end{tabular}


Table 3. Cont.

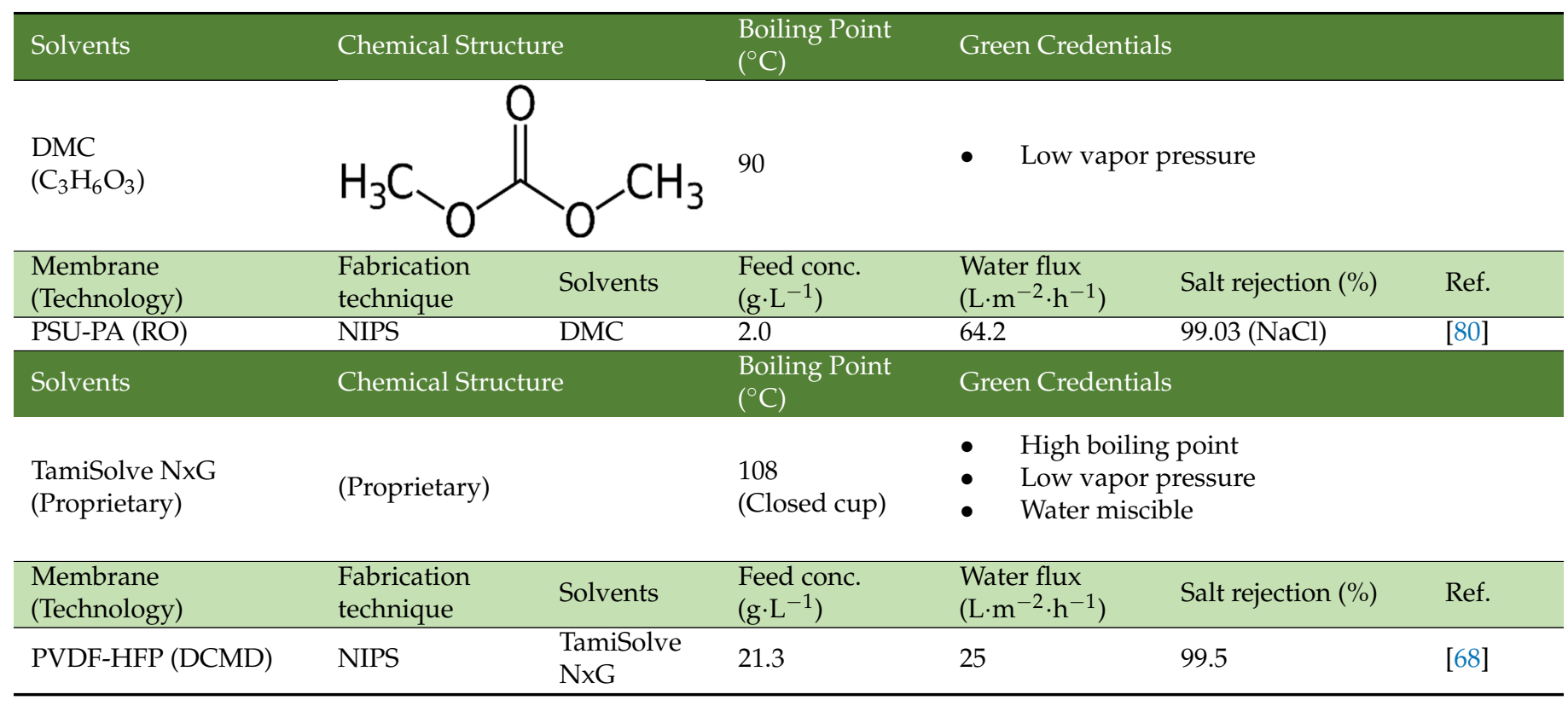

\subsection{Bio-Sourced Solvents \\ 2.3.1. Methyl Lactate}

Methyl lactate is a naturally derived ester of lactic acid, also known as lactic acid methyl ether [81]. As the simplest form chiral ether, it is a colorless liquid which shows excellent chemical properties as a non-toxic solvent for CA membrane preparation because it is biodegradable, versatile, and water miscible [69]. It can completely dissolve chloride salts and CA pellets forming a homogeneous solution to be casted. Particularly, methyl lactate is only used in the fabrication of CA UF membrane [24]. The molecular weight cut off (MWCO) of the membrane prepared using methyl lactate is around $10-500 \mathrm{kDa}$, which represents a typical UF membrane, while the percentage of solutes rejection is similar to the membranes fabricated with NMP as solvent $[82,83]$.

Medina-Gonzalez et al. [59] prepared methyl lactate as the green solvent which is in compliance with a few principles of green chemistry mentioned in the previous section. They evidenced the feasibility of fabricating a CA UF membrane using methyl lactate as a solvent and $\mathrm{CaCl}_{2}$ as porogens. With the aid of $\mathrm{CaCl}_{2}$ as porogen, the resultant membrane was pressure resistant (up to 5 bar) and defect free, with an MWCO lower than $500 \mathrm{kDa}$, making it completely possible for the rejection of some bulky-sized salts. Meanwhile, Rasool et al. [69] prepared a CA membrane using methyl lactate as solvent and 2-methyltetrahydrofuran as a co-solvent via NIPS to test for protein and salt rejections. Prior to the casted dope solution immersion in the water bath, some membranes were given extra evaporation period of $30 \mathrm{~s}$. The membranes with $30 \mathrm{~s}$ evaporation period had a higher $\mathrm{MgSO}_{4}$ rejection but lower water permeation, which was attributed by the membrane densification due to delayed mixing and a slower exchange pace between the solvent and non-solvent. The membrane with respect to best water permeation showed $80.2 \%$ of the $\mathrm{MgSO}_{4}$ rejection at $12.8 \mathrm{~L} \cdot \mathrm{m}^{-2} \cdot \mathrm{h}^{-1} \cdot \mathrm{bar}^{-1}$, while the membrane with respect to best salt rejection showed $96.5 \%$ of $\mathrm{MgSO}_{4}$ rejection at $1.1 \mathrm{~L} \cdot \mathrm{m}^{-2} \cdot \mathrm{h}^{-1} \cdot \mathrm{bar}^{-1}$. The water flux can be easily tweaked by increasing the operating pressure within the threshold limit. Judging from the green metrics, the replacement of the conventional solvents by methyl lactate is definitely feasible alongside some benefits brought to the whole process such as reduced eco-toxicity. 


\subsection{2. $\gamma$-Butyrolactone}

$\gamma$-Butyrolactone, a water-miscible, hygroscopic colorless liquid with a weak odor, is an excellent choice of non-toxic solvent for membrane fabrication. It is the simplest four-carbon lactone. Generally, it is employed as an intermediate in the production of other chemicals, such as NMP. At the same time, it can also be a good replacement of toxic solvent for membrane preparation. Song et al. [84] prepared a PVDF hollow fiber membrane via TIPS using $\gamma$-butyrolactone and dioctyl phthalate (DOP) as binary non-toxic solvents for MD. The objective of this study was to predict the possible composition to produce a bi-continuous structure in the microporous membrane. Hence, the solubility parameter theory and Flory-Huggins equation were used to deduce the quantitative relation equations between the phase separation temperature and interaction parameter. Finally, a predicted system comprised of $12.74 \mathrm{wt} . \%$ PVDF, $58.44 \mathrm{wt} . \%$ DOP and the rest $\gamma$-butyrolactone, successfully fabricated hollow fiber membranes with a desired interconnected sponge-like structure. Using $3.5 \mathrm{wt}$. $\%$ of $\mathrm{NaCl}$ solution as FS, the membrane performances were studied in DCMD test. The resulting membrane proved superior tp pure water flux $\left(51.5 \mathrm{~L} \cdot \mathrm{m}^{-2} \cdot \mathrm{h}^{-1}\right)$, while the salt rejection was able to maintain at $99.99 \%$ at all time, indicating the feasibility of the binary solvents' combination to prepare a hollow fiber MD membrane for desalination application. In addition, Bey et al. [85] reported that $\gamma$-Butyrolactone is a good replacement of toxic solvents such as DMA, DMF, and chloroform. Polyether ether ketone (PEEK-WC) hollow fiber membrane was fabricated for a hollow fiber membrane contractor (HFMC). The obtained results exhibited excellent chromium salt rejection.

\subsection{3. АТBC}

ATBC is made by the esterification of tributylcitrate and acetic acid. In TIPS, it is known as one of the most popular green solvents with low toxicity and high compatibility with several polymers that is being used to replace highly toxic phthalates for membrane preparation. ATBC is a nearly colorless and odorless oily diluent which is mainly used as the plasticizer for polyvinyl chloride, ethyl-cellulose, methacrylic, acrylic, vinyl-acetate, nitrocellulose and urethane polymer systems [86,87]. It is widely employed in the pharmaceutical, medical, food, and toys production industries [88].

Particularly, it can be used to prepare PVDF membrane via TIPS. Cui et al. [88] pioneered the use of ATBC as a green solvent in PVDF membrane preparation. The membranes were prepared in both hollow fiber and flat sheet forms. ATBC was proved to be efficacious in dissolving PVDF from a high concentration to low concentration. The morphological results showed that a high PVDF concentration could potentially improve the membrane mechanical strength but sacrifice the pure water flux. Instead, lowering the PVDF concentration and quenching temperature could enhance the pure water flux. These results potentially open a new avenue in the preparation of PVDF membrane using ATBC as an efficient yet non-toxic solvent. Hassankiadeh et al. [89] then fabricated PVDF hollow fiber membranes with different molecular weight using ATBC as a green solvent in the desalination application. Similarly, the study revealed that quenching temperature significantly affected the membrane performance while the washing temperature had a negligible effect on that. From the DCMD test, it was disclosed that the lower PVDF molecular weight granted high pure water flux due to higher mean pore size and overall porosity. More interestingly, the resulting membranes had even higher water flux in comparison with few types of commercial PVDF membranes. Meanwhile, the membrane prepared with the highest molecular weight despite having a slightly lower water flux, but was able to maintain a high salt rejection of $99.9 \%$ using $3.5 \mathrm{wt} . \% \mathrm{NaCl} \mathrm{FS}$ under all operating conditions, indicating the formation of uniform membrane structure using ATBC as a solvent.

On the other hand, Xu et al. [90] used ATBC as the solvent to prepare poly(ethylene chlorotrifluoroethylene) (ECTFE) membranes via TIPS for membrane distillation (MD) desalination. Figure 5 a shows the binary phase diagram of ECTFE/ATBC, whereby a 
wide liquid-liquid separation region is observed between ECTFE concentration of around 17 wt.\% to 48 wt.\%, while solid-liquid phase separation happens outside this ECTFE range. Liquid-liquid separation is more favorable than solid-liquid separation as the former can form a bi-continuous structure which is ideal for water transport, while the latter yields spherulite structure. It was then compared with the phase diagram (Figure $5 b$ ) of ECTFE/glycerol triacetate (GTA), ECTFE/DOP and ECTFE/diethyl phthalate (DEP) from other studies in the literature $[49,91]$, before it was noticed that the liquid-liquid phase separation of ECTFE/ATBC was much wider than the other combinations. This indicates a higher compatibility of ECTFE/ATBC compared to the other, attributed by high affinity between the solvent and the polymer. High affinity resulted in a low nucleation rate but higher nuclei growth rate as the nuclei has sufficient space for growth. Furthermore, Figure $5 \mathrm{c}-\mathrm{d}$ illustrate the cross-sectional morphologies of ECTFE membranes prepared with 20 and $40 \mathrm{wt} . \%$ of ECTFE at $20^{\circ} \mathrm{C}$ quenching temperature. It can be noticed that a higher polymer concentration would increase the spherulite density, which eventually resulted in a narrower gap between the spherulites, leading to smaller membrane pore size and porosity. However, the ideal bi-continuous structure was not observed owing to the fact that the quenching temperature of $20{ }^{\circ} \mathrm{C}$ was too low leading to a high cooling rate, and the separation duration was too short to form a bi-continuous structure. The quenching temperature was increased to $80^{\circ} \mathrm{C}$ to prolong the cooling rate. As illustrated in Figure 5e, larger spherulite structure with a tighter gap was produced and eventually intertwined together, forming a bi-continuous structure. In addition, by increasing the concentration of ECTFE, a similar trend was observed in the previous PVDF membrane studies, wherein reduced water fluxes and improved mechanical strength were observed due to the increased membrane integrity. Substantially, the membrane with the most optimal ECTFE loading exhibited a decent pure water flux of $22.3 \mathrm{~L} \cdot \mathrm{m}^{-2} \cdot \mathrm{h}^{-1}$ and $\mathrm{NaCl}$ rejection of $99.9 \%$, making the ECTFE membrane in MD desalination completely viable with ATBC as an environmentally benign diluent. 
(a)

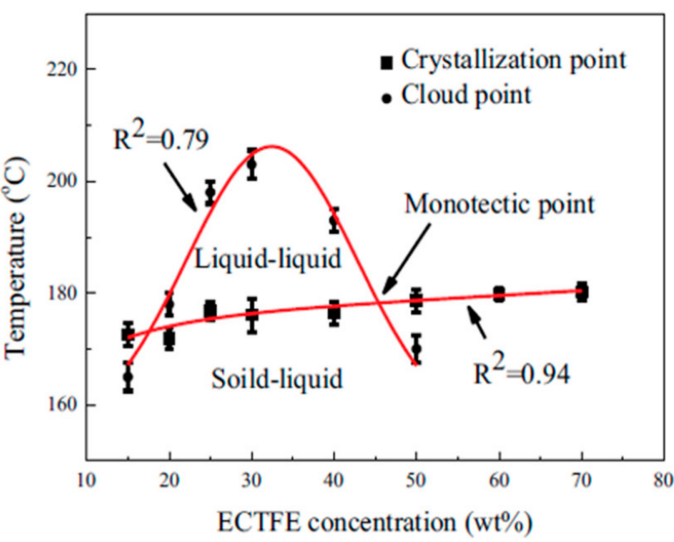

(c)

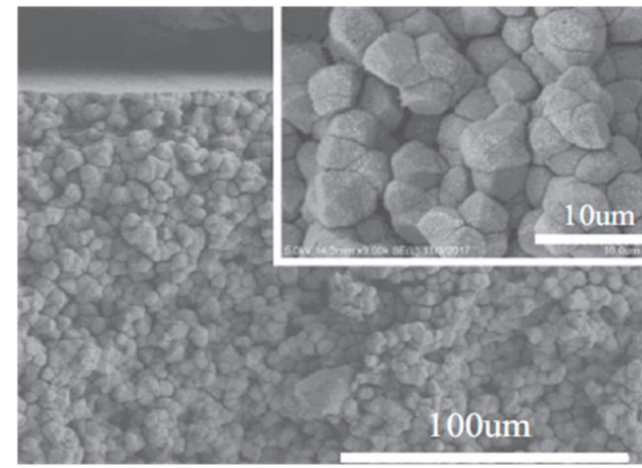

(b)

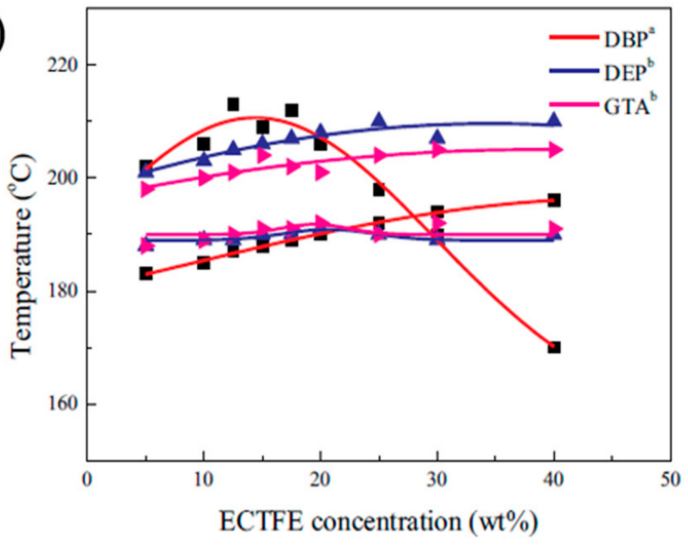

(d)

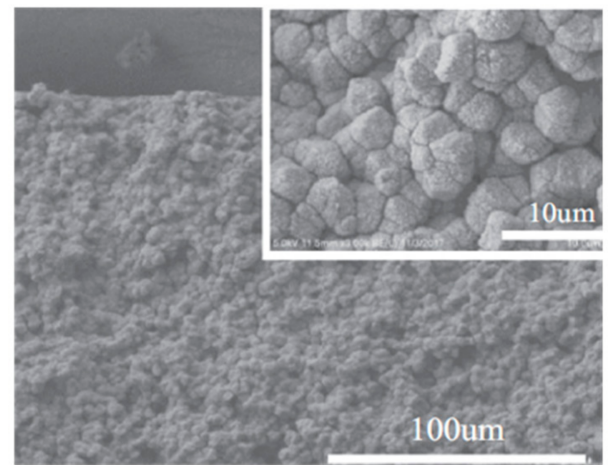

(e)

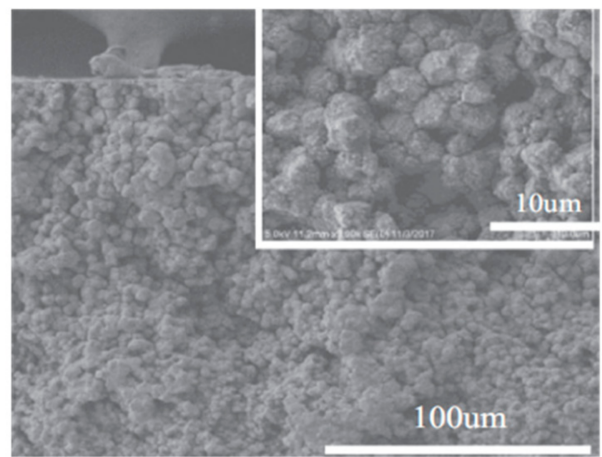

Figure 5. (a) Phase diagram of poly(ethylene chlorotrifluoroethylene) (ECTFE)/ATBC; (b) phase diagram of ECTFE/glycerol triacetate (GTA), ECTFE/DBP and ECTFE/ diethyl phthalate (DEP); (c,d) cross-sectional morphologies of ECTFE membrane with a polymer concentration of 20 and $40 \mathrm{wt}$.\% at a quenching temperature of $20^{\circ} \mathrm{C}$; (e) cross-sectional morphologies of ECTFE membrane with a polymer concentration of $30 \mathrm{wt} . \%$ at a quenching temperature of $80^{\circ} \mathrm{C}$ [90].

\subsubsection{Soybean Oil}

Soybean is one of the most important agricultural commodities in the world, devoting around USD 50 to the world's total economy. Soybean also accounts for around $57.03 \%$ of all oil crops (including oilseed), making it the top global oil crop [92]. Hence, soybean is highly accessible, and soybean oil has also become one of the most important vegetable oils in the world. More than $96 \%$ of the soybean oil produced commercially is used in the food production industry such as margarine, salad oil, cooking oil, and shortening. Solvent extraction is the widely used industrial method of extracting soybean oil as the solvent considering the low oil content of soybean [93]. Its chemical properties, zero toxicity nature, and high accessibility has possibly made it an alternative solvent replacement for membrane application [94]. The first attempt of using soybean oil as the solvent in desalination membrane preparation was reported by Tang et al. [95]. The green solvent was used to prepare isotactic polypropylene (IPP) hydrophobic flat sheet membrane via 
TIPS. Homogeneous doping solution was able to be formed within 25-32 wt. $\%$ of IPP, with $70-80 \%$ of the resulting IPP membranes' pore size ranging from 0.02 to $0.2 \mu \mathrm{m}$. Soybean oil proved to be a good solvent for the fabrication of the narrow pore size distribution IPP membrane. The pore size distribution could be slightly narrower by increasing the IPP melt index with a quenching temperature of $20-30{ }^{\circ} \mathrm{C}$. Overall, soybean oil as a solvent yields consistent performance over a quenching temperature range with a minor effect on membrane porosity. It had a nearly insignificant effect on the membrane formation. On the other hand, the IPP membrane with $27 \mathrm{wt} . \%$ had the most optimum performance, with a pure water flux of $24.81 \mathrm{~L} \cdot \mathrm{m}^{-2} \cdot \mathrm{h}^{-1}$ and an $\mathrm{NaCl}$ rejection of $>99.9 \%$.

Wang et al. [96] employed non-toxic binary solvents, soybean oil and carnauba wax in a novel fabrication approach for PP membranes via TIPS. Carnauba wax can be easily crystallized and recycled by cooling after being extracted by boiling ethanol. Carnauba wax was the first solvent investigated and determined that the addition of carnauba wax to soybean oil could shift the solid-phase separation into liquid-phase separation. The liquid-liquid phase separation region, whereby the separation of molecules occurs through condensation into a denser phase resembling liquid droplets, can be further expanded by continuously increasing the carnauba wax concentration. A wider liquid-liquid separation region could facilitate the membrane fabrication, producing desired membranes with completely interconnected sponge-like pore structure. Soybean oil was secondly added as the latent solvent and the effects of solvents' composition on the membrane morphologies and performance were investigated. It is crucial to strike a balance between the mechanical strength of the membrane and water permeation, as a higher carnauba wax ratio can significantly reduce the membrane mechanical strength but improve water permeation due to the increased porosity. The resulting PP membrane had an interconnected spongelike structure formed, which significantly improved membrane elongation at break. At a carnauba wax/soybean oil ratio of $3 / 7$ with $20 \mathrm{wt} . \%$ PP concentration, the resulting membrane exhibited an astonishing performance reaching $41.2 \mathrm{~L} \cdot \mathrm{m}^{-2} \cdot \mathrm{h}^{-1}$ water flux and $99.95 \%$ salt rejection without any salt leakage being observed. Table 4 shows the summary of previous works from several authors using bio-sourced solvents in membrane fabrication for desalination.

Table 4. The characteristics of synthetic organic solvents and their summarized studies in membrane desalination.

\begin{tabular}{|c|c|c|c|c|c|}
\hline Solvents & Chemical Structure & Boiling Point $\left({ }^{\circ} \mathrm{C}\right)$ & \multicolumn{3}{|c|}{ Green Credentials } \\
\hline $\begin{array}{l}\text { Methyl lactate } \\
\left(\mathrm{C}_{4} \mathrm{H}_{8} \mathrm{O}_{3}\right)\end{array}$ & & 144 & $\begin{array}{ll}\text { - } & \text { Biodegr } \\
\text { - } & \text { Water } \mathrm{m}\end{array}$ & & \\
\hline $\begin{array}{l}\text { Membrane } \\
\text { (Technology) }\end{array}$ & $\begin{array}{l}\text { Fabrication } \\
\text { technique }\end{array}$ & Feed conc. $\left(\mathrm{g} \cdot \mathrm{L}^{-1}\right)$ & $\begin{array}{l}\text { Water flux } \\
\left(\mathrm{L} \cdot \mathrm{m}^{-2} \cdot \mathrm{h}^{-1}\right)\end{array}$ & $\begin{array}{l}\text { Salt rejection } \\
(\%)\end{array}$ & Ref. \\
\hline $\mathrm{CA}(\mathrm{NF})$ & $\begin{array}{l}\text { Methyl lactate/ } \\
\text { 2-Methyl THF } \\
\text { (Co-solvent) }\end{array}$ & 0.6 & 134.4 & $80.2\left(\mathrm{MgSO}_{4}\right)$ & [69] \\
\hline Solvents & Chemical Structure & Boiling Point $\left({ }^{\circ} \mathrm{C}\right)$ & Green Creder & & \\
\hline $\begin{array}{l}\gamma \text {-Butyrolactone } \\
\left(\mathrm{C}_{4} \mathrm{H}_{6} \mathrm{O}_{2}\right)\end{array}$ & & 204 & $\begin{array}{ll}\text { - } & \text { High bo } \\
\text { - } & \text { Low var } \\
\text { - } & \text { Biomass } \\
\text { - } & \text { Biodegr }\end{array}$ & $\begin{array}{l}\text { point } \\
\text { ressure } \\
\text { ivation } \\
\text { le }\end{array}$ & \\
\hline $\begin{array}{l}\text { Membrane } \\
\text { (Technology) }\end{array}$ & $\begin{array}{l}\text { Fabrication } \\
\text { technique }\end{array}$ & Feed conc. $\left(\mathrm{g} \cdot \mathrm{L}^{-1}\right)$ & $\begin{array}{l}\text { Water flux } \\
\left(\mathrm{L} \cdot \mathrm{m}^{-2} \cdot \mathrm{h}^{-1}\right)\end{array}$ & $\begin{array}{l}\text { Salt rejection } \\
(\%)\end{array}$ & Ref. \\
\hline PEEK-WC (HFMC) & $\gamma$-Butyrolactone & $0.01-0.1$ & - & 99.0 (Cr salt) & [85] \\
\hline PVDF (DCMD) & $\gamma$-Butyrolactone & 3.5 wt. $\%$ & 51.5 & $99.99(\mathrm{NaCl})$ & [84] \\
\hline
\end{tabular}


Table 4. Cont.

\begin{tabular}{|c|c|c|c|c|c|}
\hline Solvents & Chemical Structure & Boiling Point $\left({ }^{\circ} \mathrm{C}\right)$ & \multicolumn{3}{|c|}{ Green Credentials } \\
\hline $\operatorname{ATBC}\left(\mathrm{C}_{20} \mathrm{H}_{34} \mathrm{O}_{8}\right)$ & & 327 & \multicolumn{3}{|c|}{$\begin{array}{ll}\text { - } & \text { Biodegradable } \\
\text { - } & \text { High boiling point } \\
\text { - } & \text { Low vapor pressure }\end{array}$} \\
\hline $\begin{array}{l}\text { Membrane } \\
\text { (Technology) }\end{array}$ & $\begin{array}{l}\text { Fabrication } \\
\text { technique }\end{array}$ & Feed conc. $\left(\mathrm{g} \cdot \mathrm{L}^{-1}\right)$ & $\begin{array}{l}\text { Water flux } \\
\left(\mathrm{L} \cdot \mathrm{m}^{-2} \cdot \mathrm{h}^{-1}\right)\end{array}$ & $\begin{array}{l}\text { Salt rejection } \\
(\%)\end{array}$ & Ref. \\
\hline PVDF (DCMD) & TIPS & 3.5 wt. $\%$ & $\sim 21$ & $99.9(\mathrm{NaCl})$ & [89] \\
\hline ECTFE (VMD) & ATBC & 3.5 wt. $\%$ & 22.3 & $99.9(\mathrm{NaCl})$ & [90] \\
\hline Solvents & Chemical Structure & Boiling Point $\left({ }^{\circ} \mathrm{C}\right)$ & \multicolumn{3}{|c|}{ Green Credentials } \\
\hline $\begin{array}{l}\text { Soybean Oil } \\
\left(\mathrm{C}_{57} \mathrm{H}_{98} \mathrm{O}_{12}\right)\end{array}$ & & 300 & \multicolumn{3}{|c|}{$\begin{array}{ll}\text { - } & \text { Biomass derivation } \\
\text { - } & \text { Biodegradable } \\
\text { - } & \text { High boiling point }\end{array}$} \\
\hline $\begin{array}{l}\text { Membrane } \\
\text { (Technology) }\end{array}$ & $\begin{array}{l}\text { Fabrication } \\
\text { technique }\end{array}$ & Feed conc. $\left(\mathrm{g} \cdot \mathrm{L}^{-1}\right)$ & $\begin{array}{l}\text { Water flux } \\
\left(\mathrm{L} \cdot \mathrm{m}^{-2} \cdot \mathrm{h}^{-1}\right)\end{array}$ & $\begin{array}{l}\text { Salt rejection } \\
(\%)\end{array}$ & Ref. \\
\hline IPP (VMD) & Soybean oil & 29.22 & 24.81 & $>99.9(\mathrm{NaCl})$ & [95] \\
\hline PP (VMD) & $\begin{array}{l}\text { Soybean } \\
\text { oil/carnauba wax }\end{array}$ & 10 & 41.2 & $99.95(\mathrm{NaCl})$ & [96] \\
\hline
\end{tabular}

\subsection{Ionic Liquids}

Ionic liquids are another great alternative to replace environmentally harmful solvents. Compared to the volatile solvents, ionic liquids with extremely low vapor pressure produced nearly zero VOCs, hence imposing minimum health risks on the operators. Due to their promising applications in many areas such as catalysis [97], polymer synthesis [98], and battery [99], some industries have started to replace traditional solvents with ionic liquids. However, some controversies have arisen, stating that the toxicity of ionic liquids in water remains inconclusive and the sustainability of their production life cycle assessment has not been thoroughly investigated [100]. There is a broad variety of ionic liquids for different types of applications and polymers, and all of them are made up of positive and negative ions. The cation could be pyridinium, imidazolium, quarternary ammonium or quarternaryphosphonium, while the anion could be halogen, trifluoroborate, triflate, or hexafluorophosphate [101]. Ionic liquids possess strong solvency power to dissolve a high concentration of molecules or even biopolymers with limited solubility in traditional solvents.

It is worth noting that some ionic liquids are harmful, and the production route can be quite hard [102]. Nonetheless, their green credential owing to negligible vapor pressure in contrast to the traditional VOCs, as well as excellent versatility, make them a good choice to replace traditional solvents. In membrane application, Xing et al. [103] used ionic liquid 1-ethyl-3-methylimidazolium acetate with low toxicity as an alternative solvent to prepare a polybenzimidazole (PBI) membrane for nanofiltration. 1-ethyl-3methylimidazolium acetate is highly miscible in water and liquid at room temperature. Compared to other ionic liquids, 1-ethyl-3-methylimidazolium acetate has strong dissolving power even at low viscosity and water content; it is a great hydrogen bond acceptor. As for DMI, 1-ethyl-3-methylimidazolium acetate ([EMIM]OAc) was able to dissolve PBI more efficiently under low pressure and temperature, which was attributed to the strong ionic interaction of 1-ethyl-3-methylimidazolium acetate to break down the hydrogen bonds and $\pi-\pi$ interaction in PBI [104]. The resulting membrane had a thick sponge-like structure with several macrovoids and exhibited decent performance for water flux $\left(26.05 \mathrm{~L} \cdot \mathrm{m}^{-2} \cdot \mathrm{h}^{-1}\right)$ and solute rejection (>95\%). Additionally, 1-ethyl-3-methylimidazolium acetate is miscible with water at any scale, making them prone to leaching after membrane casting for further recycling and reuse purposes. 
In cellulosic membrane preparation, ionic liquids are among the very few solvent able to dissolve cellulose, mainly driven by its anionic groups. This greatly reduces the environmental issue as cellulose is the most abundant renewable resource, however, it is insoluble in most of traditional solvents. Ding et al. [105] were the first group of researchers who studied the fundamental differences in membrane formation between ionic liquid and traditional solvents (NMP and acetone) during the phase inversion of the CA membrane. The membrane formed using ionic liquid 1-butyl-3-methylimidazolium thiocyanate as a solvent, had a dense macrovoid-free structure full of nodules, indicating that the membrane formed via the slow process of nucleation growth and gelation. Then, the ionic liquids were recovered and reused. The resulting membrane formed using recovered solvent exhibited performance and morphologies similar to those prepared from the fresh solvent. Livazovic et al. [106] used 1-ethyl-3-methylimidazolium acetate to prepare multilayer membranes consisting of few polymers, and cellulose as the selective layer. The counterpart of silylated cellulose in tetrahydrofuran was produced as a benchmark. The cellulose silylation inhibits the formation of a hydrogen bond and creates hydrophobic cellulose soluble in tetrahydrofuran. The membrane prepared using ionic liquids had a water permeance of $13.8 \mathrm{~L} \cdot \mathrm{m}^{-2} \cdot \mathrm{h}^{-1} \cdot \mathrm{bar}^{-1}$ and a MWCO of $3000 \mathrm{~g} \cdot \mathrm{mol}^{-1}$, outperforming the silylated membrane in both water permeance $\left(8.1 \mathrm{~L} \cdot \mathrm{m}^{-2} \cdot \mathrm{h}^{-1} \cdot \mathrm{bar}^{-1}\right)$ and MWCO $\left(5000 \mathrm{~g} \cdot \mathrm{mol}^{-1}\right)$. The $\mathrm{NaCl}$ rejection of the latter was as low as $3 \%$, which, however, was not being experimented with for a membrane prepared with ionic liquids. The cellulose membranes were also prepared without any polymeric supports and were confirmed to be insoluble in a series of traditional solvents. This proves the feasibility of using ionic liquids for cellulose dissolution, as well as the practicability of cellulosic membrane in various applications involving a solvent medium. On the other hand, ionic liquids such as 1-ethyl-3methyimidazolium diethyl phosphate, 1,3-dimethylimidazolium dimethyl phosphate, and 1-butyl-3-methylimidazolium chloride were also employed by other groups of researcher as the solvent to prepare cellulosic membrane for dye, protein, and oil retentions [107-109]. The membrane performances showed that all ionic liquids can be good solvents for cellulose. Table 5 shows the summary of previous works from several authors using ionic liquids as solvents in membrane fabrication for desalination.

Table 5. Characteristics of ionic liquids and their summarized studies in membrane desalination.

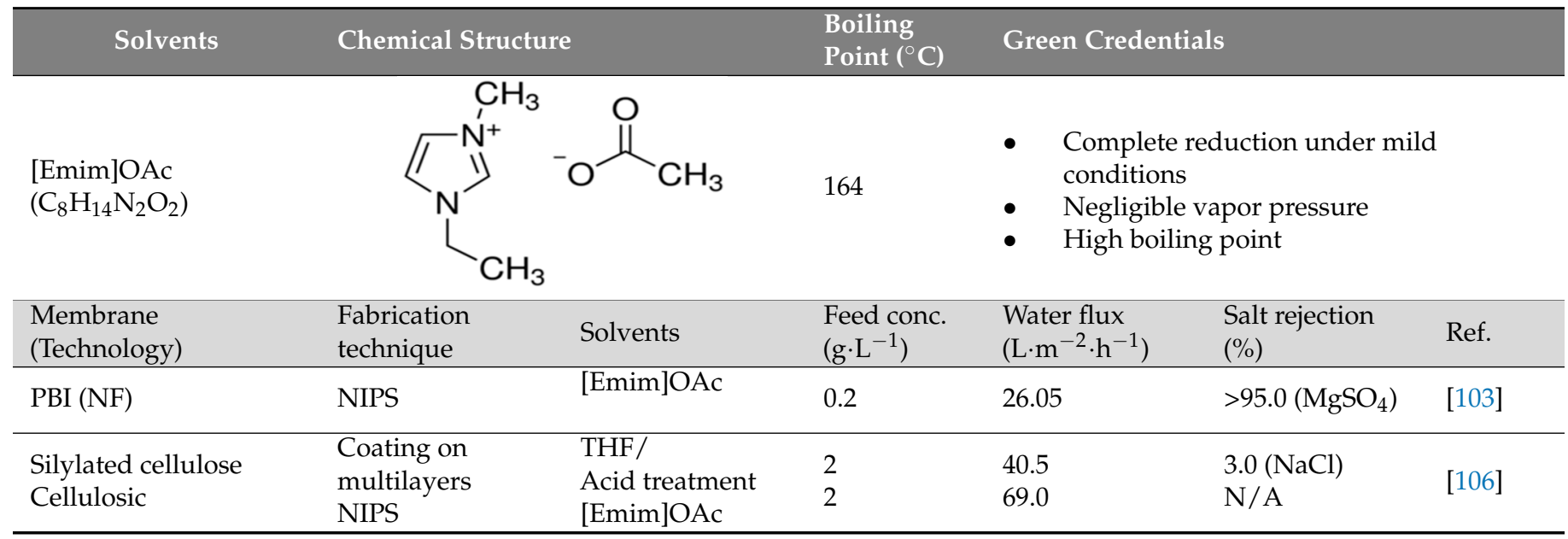

\subsection{Other Potential Green Solvents}

In addition, there are still numerous green solvents being used in membrane fabrication, such as glycerol triacetate (GTA) [110], triethylene glycol diacetate (TEGDA) [66], ATEC [65], ATBC [65], and methyl-5-(dimethylamino)-2-methyl-5-oxopentanoate (Rhodiasolv ${ }^{\circledR}$ PolarClean) [111,112], Cyrene ${ }^{\mathrm{TM}}$ [113], just that their application in desalination for the current state is scarcely found. However, as the whole scientific community is working harder towards achieving a sustainable green objective, it is expected that more exploration as well 
as studies for the great use of green solvents in membrane desalination will be available in the future.

\section{Membrane Modification}

Since the invention of membranes for desalination, these have undergone huge developments from time to time in terms of material science, synthesis methods, membrane modification, as well as process and system optimization [114]. Among the materials used to synthesize a desalination membrane, the PA-TFC membrane prepared via IP is by far the most popular due to its superior water permeability and salt rejection properties [115]. However, the permeability/rejection trade-off has affected the performance effectiveness. Efforts have been made to address such a bottleneck whereby membrane modification in general serves this purpose well. Alongside with the membrane community growth, tons of excellent, interesting and novel modification ideas and methods are gradually discovered to tackle the thorny challenge. Membrane modifications are flexible as different combinations and routes could potentially yield different outcomes to cater to the need. For instance, in the FO or RO process, it can be performed to enhance water flux and solute rejection, as well as to minimize fouling propensity, while in FO alone, it can solve the internal concentration polarization (ICP) phenomenon and reduce the reverse solute flux [116-118]. Although many modification approaches have been established, most of them require solvent. This review only focuses on sustainable approaches, which are mainly the solvent-free methods.

\subsection{Click Chemistry for Membrane Modification}

The click chemistry which was proposed in 2001 has become popular due to its robust and effective reactions [119]. It is an environmentally benign chemical reaction as it is mostly performed under non-stringent conditions such as room temperature and atmospheric pressure without consuming much external energy and producing inoffensive by-products which can be easily removed by non-chromatographic method (such as distillation and crystallization). Ideally, the process is insensitive to water and oxygen. There are wide scopes of reactants that can be used to carry out such reactions to produce a highly selective and highly yielded product (stereospecific) [119,120]. The reaction is known as the "spring loaded process" for a single trajectory as it has a thermodynamic driving force higher than $20 \mathrm{kcaL} \cdot \mathrm{mol}^{-1}$ which makes the process rapid. The few most common click chemistries involving carbon-heteroatom bond forming include cycloaddition of unsaturated compound (1,3-dipolar cycloaddition), nucleophilic substitution reaction (ring opening reactions of strained heterocyclic electrophiles), carbonyl reaction of the "non-aldol" compound, additions to carbon-carbon multiple bonds (epoxidation, aziridination, dihydroxylation, etc.). Among all, azide-alkyne 1,3-dipolar cycloaddition or Huisgen 1,3-dipolar cycloaddition is the most commonly employed reaction, which is the usually referred "click reaction" [121].

The first breakthrough of the reaction was based on the introduction of copper (I) as a catalyst into the reaction in 2002 [122,123]. However, the copper-based reaction introduces cytotoxicity to the environment, especially to the biological system [124]. This potentially limits its application in certain practical situations, such as bioconjugation. Hence, copper (I)-free azide-alkyne 1,3-dipolar cycloaddition is introduced as a green alternative to overcome such a problem and has been widely adopted until today. However, the copper-free reaction comes with the compensation of being a rather slow, high temperature, and unselective process. Figure $6 \mathrm{a}, \mathrm{b}$ show the cycloaddition reactions without and with copper (I) as the catalyst, respectively, whereby the equimolar mixture of 1,4- and 1,5disubstituted 1,2,3-triazoles regioisomers are produced in the absence of copper. However, with a catalytic amount of copper (I), the reaction can be accelerated up to seven-fold with improved regioselectivity, forming 1,4- disubstituted isomer as the sole product. Lately, click chemistry is brought into membrane modification such as the nanofiller incorporation [125], post-polymerization modification [126], layer-by-layer (lbl) assembly [127], 
as an effective and eco-friendly approach to replace some current modification technologies. Figure $7 \mathrm{a}-\mathrm{c}$ further illustrate the application of click reaction in different membrane modification techniques.<smiles>[R]CCC</smiles><smiles>[R]C#C[C-]C</smiles>

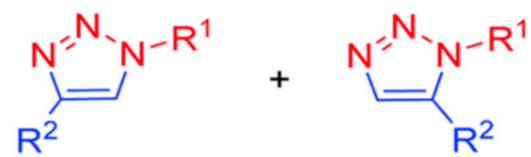<smiles>[R2]c1cn([R])nn1</smiles>

Figure 6. (a) Huisgen 1,3-dipolar cycloaddition; and (b) copper-catalyzed 1,3-dipolar cycloaddition [128].

(a)

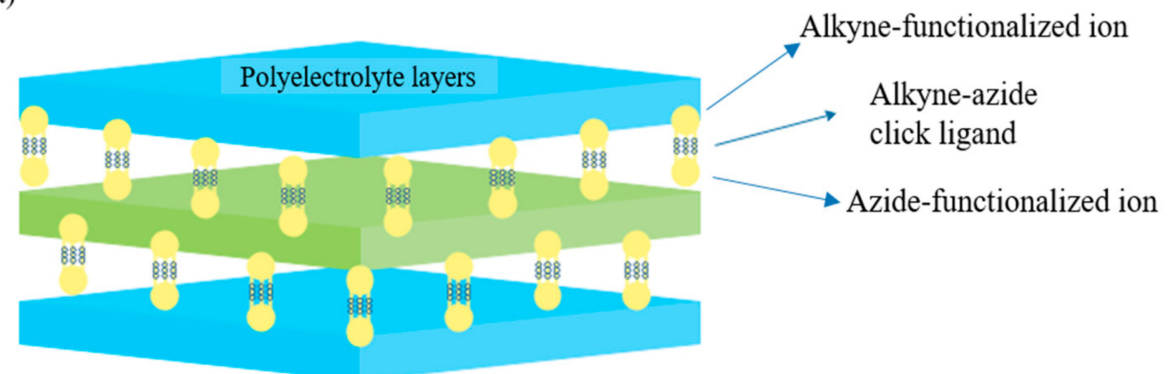

(b)

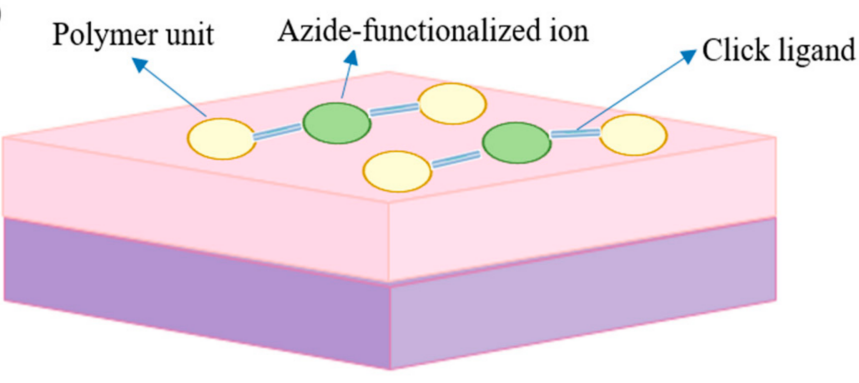

(c) Polymer unit

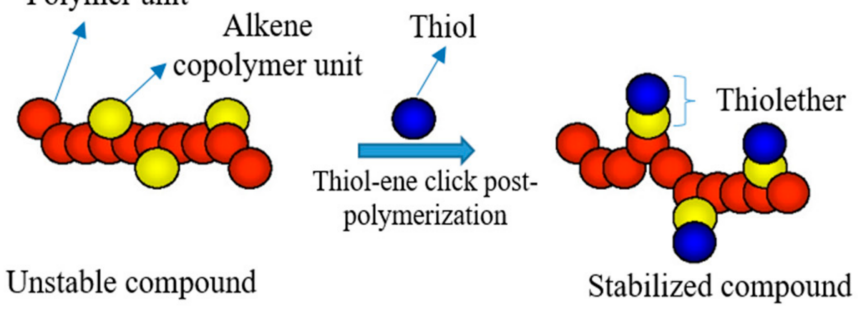

Figure 7. Click reaction in: (a) layer-by-layer (lbl) assembly technique; (b) nanofiller modification; and (c) post-polymerization modification.

\subsubsection{Layer-by-Layer Assembly}

$\mathrm{Lbl}$ assembly technique is a promising method to prepare membrane with an ultrathin selective layer which has good rejection towards divalent ions as well as strong thermal stability that has been successfully employed for NF operations throughout the years [129]. The lbl method involves the deposition of several polyelectrolytes with opposite charges onto porous substrate surface in alternate sequence. The first polyelectrolyte layer on the porous support layer is usually linked by electrostatic attraction or hydrophobic attraction. 
The $\mathrm{lbl}$ technique can be easily employed to produce composite polyelectrolyte multilayer membranes to obtain improved water flux and rejection. Despite the acceptable rejection for divalent ions such as $\mathrm{Mg}^{2+}$ and $\mathrm{SO}_{4}{ }^{2-}$, the retention of monovalent ions such as $\mathrm{Na}^{+}$is remarkably low due to the relatively loose selective layer. As membrane fouling persists as one of the thorniest issues in RO operation, the strong surface charge of the selective layer is crucial to reduce membrane fouling. In order to potentially improve the membrane performances while minimizing fouling, Wang et al. [130] assembled polyethylene glycol (PEG) acrylate multilayers via the $\mathrm{lbl}$ technique on a commercial RO membrane and stabilized using click reaction. As the number of PEG bilayers increased, the fouling resistance of the membrane surface improved significantly. It is worth noting that the water flux did not suffer a severe decline owing to the addition of PEG bilayers, in which only a mere decline of $9-17 \%$ was observed. Additionally, the lbl assembly using click reaction was able to ensure the membrane thickness in the nanometer range for maximum effectiveness, as each PEG bilayer coated with click chemistry was only around $3.9 \mathrm{~nm}$. Using such click chemistry to covalently bond the multiple films also grants the benefit of being ultra-stable, whereby the occurrence of disassembly is not likely to be observed under varying conditions (e.g., pH). From the seawater $\mathrm{RO}$ test, it was observed that despite undergoing $27 \mathrm{~h}$ operation, the resulting $\mathrm{lbl}$ membrane with 2-bilayer was able to retain a high water flux of around $110 \mathrm{~L} \cdot \mathrm{m}^{-2} \cdot \mathrm{h}^{-1}$ and salt rejection of $>94.5 \%$.

Similarly, Cho et al. [130] fabricated a cross-linked lbl PSU membrane by spray coating with polyallylamine hydrochloride (PAH) and polyacrylic acid (PAA) polyelectrolytes. Azide-alkyne click reaction accounted for the polyelectrolytes cross-linking, which also removed the chemical or thermal post-coating treatment. The PAA was functionalized with alkyne while the PAH was functionalized with azide, and spray coating was performed for a duration of $20 \mathrm{~min}$ between each layer to allow the complete formation of 1,2,3-triazole linkage. The lbl assembly performed in such way that produced a polyelectrolyte layer with reduced coiling and thus smaller pores and improved rejection. The coating of the PAA polyanion layer resulted in increased water flux and decreased salt rejection, indicating the increase in membrane free volume. For the divalent $\mathrm{CaCl}_{2}$ salt, the rejection could be up to $80 \%$; while for the monovalent $\mathrm{NaCl}$ salt, a rather unsatisfied rejection $(50 \%)$ was observed. The study revealed that the structure of the resulting multilayer membrane was significantly influenced by its deposition method and the polyelectrolytes charge density. "Click" lbl deposition was proven as a feasible approach for NF desalination, however, for RO desalination, especially when dealing with monovalent salts, further development is required to hit a remarkable rejection height. A similar outcome was found in a study by Wang et al. [131], in which tubular ceramic multilayer membranes were fabricated via a clickable lbl assembly for dye desalination. PAA and poly(vinyl) alcohol were employed as the polyelectrolyte layers pre-cross-linked by glutaraldehyde (GA). The 96\% Congo red rejection and $3 \% \mathrm{NaCl}$ rejection indicated that the multilayer membrane was only feasible for NF but not RO application. The author concluded that a covalently clicked multilayer membrane has greater stability than a electrostatically bonded multilayer membrane.

\subsubsection{Modification with Nanomaterials}

Generally, nanofiller modification serves the purpose of improving the surface hydrophilicity of a thin-film nanocomposite (TFN) membrane while reducing fouling. Meanwhile, it could also potentially affect the transport phenomena such as water transport and reverse solute diffusion. He et al. [128] prepared a novel aquaporin-based biomimetic PSU membrane using propargyl functionalized $\beta$-sheet peptide (FBP). To stabilize the aquaporin, the FBP was introduced to bind to it and form a stable peptide-protein complex in the aqueous medium, covalently conjugated with azide groups. The PSU polymers were first conjugated with a 1.05 azide group per repeating unit, followed by casting into a thin film support layer via NIPS. The peptide-protein complex was then "clicked" onto the support layer using a self-designed circulating system. The functional group analysis and surface morphology analysis indicated the successful incorporation of the peptide-protein 
complex. Compared to the previous strategies of incorporating aquaporin thin film onto membrane, the authors determined that by employing FBP and the click reaction, covalent bonding with stronger interaction and higher stability under high flow rate and pressure could be obtained. It was noticed that the salt rejection of the resulting membrane merely improved from 5 to $12.5 \%$. Click reaction is feasible in conjugating a protein thin layer onto the polymeric support layer while maintaining its functionality. However, the suboptimal improvement of the salt rejection (12.5\%) showed that there could be defects in the membrane, which might be from the low degree of click conjugation upon the pores directly. It can be accomplished by altering the casting condition or tightly binding several complexes in the membrane pores with optimized click reaction to obtain a support layer with a pore size similar to the protein complex.

For FO application, click modification often offers more advantages such as reducing structural parameters and ICP in addition to granting water permeability and antifouling performance [132]. The structural parameter is the quantitative measurement used to indicate the level of ICP, while ICP is a highly undesirable phenomenon in FO which can lead to very poor FO efficiency by limiting the water flux up to $99.9 \%[133,134]$. Zhou et al. [135] prepared a TFC FO membrane via click reaction for structural parameter reduction. Modification was done on the PSU substrate by blending or click-grafting it with different molecular weights and ratios of methoxypolyethylene glycol (mPEG). Precedent procedures were carried out on $\mathrm{MPEG}$ and PSU prior to the click-grafting of $\mathrm{mPEG}$ onto PSU to form a PSU-g-mPEG substrate as illustrated in Figure 8a. The prepared substrate was then coated with a PA layer via IP forming the TFC membrane. Compared to the mPEG-PSU membrane prepared using the blending technique, the click-grafted membrane offers more stable and higher water flux which can be seen from the flux test result in Figure $8 b$, due to the fact that mPEG could more easily concentrate on the membrane skin and inner pore surfaces, and harder to leach out during the filtration process. Compared to the pristine TFC membrane, the click-modified TFC membrane exhibited a sharp drop in structural parameters and a significant improvement in pure water flux due to the hydrophilic click-grafting of mPEG. Meanwhile, the salt rejection remained the same for all membranes, modified or unmodified, the value of which was not mentioned in the study.

Soroush et al. [136] incorporated Ag-graphene oxide (GO) onto a commercial FO TFC membrane to impart hydrophilicity and anti-biofouling properties to the membrane. Cysteamine solution was used to functionalize the surface of the TFC membrane to provide a membrane surface with thiol functionality for click reaction between $\mathrm{Ag}-\mathrm{GO}$ and amine groups of cysteamine. The functionalization was successful when the unreacted acyl halide groups from the PA layer reacted with the amine groups of cysteamine via click reaction forming strong amide bonds. The approach is more effective than the conventional modification approaches as just a lower material cost and easier preparation method are required. Minor flux reduction was observed compared to the pristine TFC due to the formation of an extra $\mathrm{Ag}-\mathrm{GO}$ layer on the membrane surface which hinders the water transport mechanism. Nonetheless, remarkable anti-biofouling improvement was observed, whereby the modified membrane had a bacterial inactivation of $>95 \%$ compared to $\sim 0 \%$ of the pristine TFC membrane.

Meanwhile, Yu et al. [137] grafted polyzwitterions (PZs) onto the TFC membrane surface using click chemistry to improve its antifouling performance for FO desalination. Click chemistry introduces a much milder approach in contrast to the harsh conditions usually needed by many traditional grafting methods, in which SN2 nucleophilic substitution on nitrogen of the PA chain could occur under mild conditions. Briefly, alkyne-PZs was first prepared via reversible addition-fragmentation chain-transfer radical polymerization. Then, the PA layer was brominated followed by the SN2 nucleophilic substitution of the $\mathrm{Br}$ group with an azide functional group. Finally, the alkyne-PZs were grafted onto the azide-PA via cycloaddition click reaction (Figure 9). The water flux of the PZs-TFC membrane was fairly affected by the click grafting, and instead, the antifouling properties of the resulting membrane improved tremendously due to the hydration layer which acted 
as a barrier on the membrane surface, the strong hydrophilic repulsion caused by the charge-induced hydration force, and the steric hindrance by the brush-like bulky PZ chains. The flux recovery of the PZs-TFC membrane was nearly $100 \%$ while that of the control membrane was only $77 \%$.

(a)

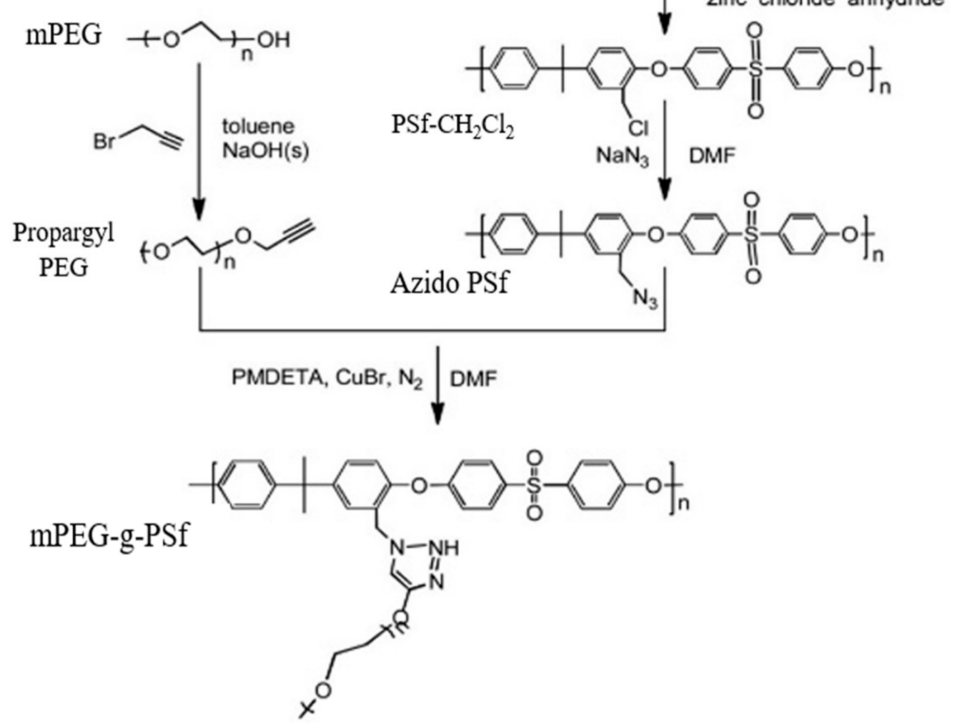

(b)

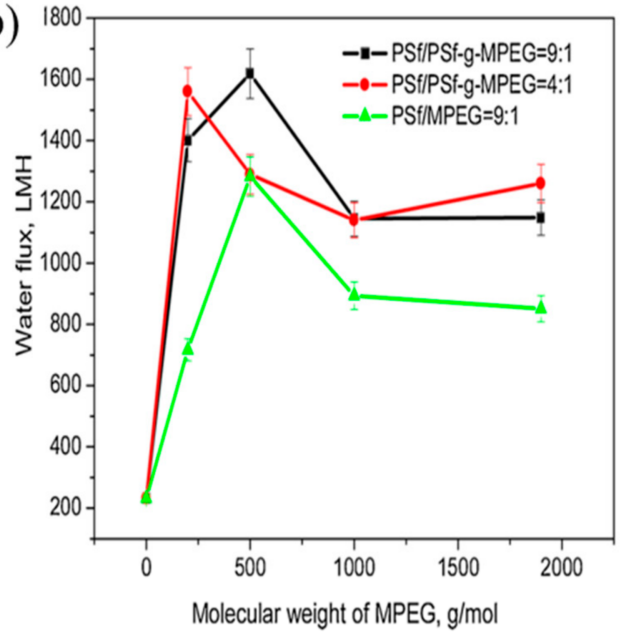

Figure 8. (a) Schematic representation of the preparation of alkynyl- methoxypolyethylene glycol (mPEG), chlorinated PSU, azido-PSU and the click reaction between alkynyl-mPEG and azido-PSU to obtain mPEG-g-PSU; and (b) the water flux test for the substrate membrane [135].

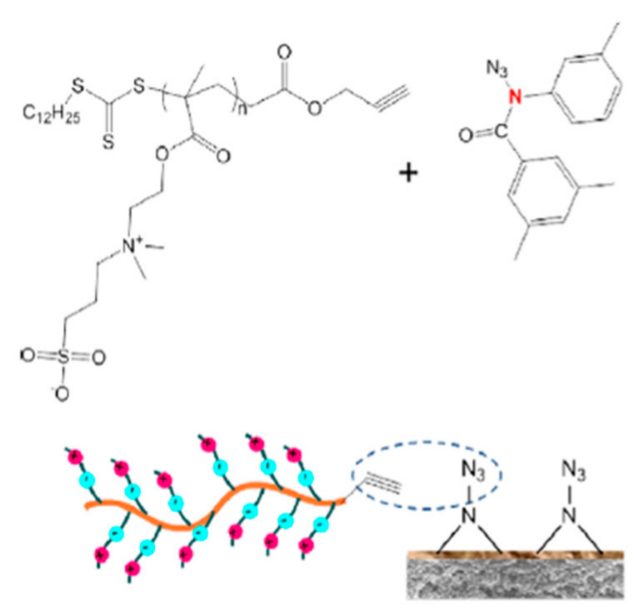

Alkyne-PZ

Azide-PA

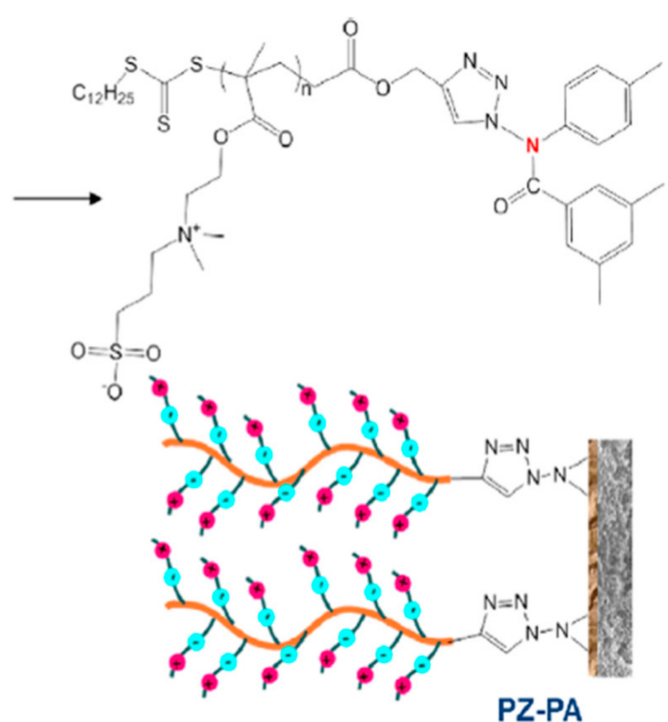

PZ-PA

Figure 9. Click chemistry of azide-PA and alkyne-polyzwitterions (PZs) with their respective chemical structure shown on top.

\subsubsection{Post-Polymerization Modification}

Often, post-polymerization modification is required to stabilize the polymer product as it could be unstable and become reversible. For instance, Yang et al. [129] used thiolene click reaction to carry out a post-polymerization modification for preparing a zwitterionic 
PSU-TFC membrane with superior hydrophilicity and antifouling behavior for the RO desalination. The purpose of the post-polymerization click modification was mainly to ensure the stability of the zwitterion copolymer formed. At first, the tertiary amines and ring-opened sultone were successfully introduced to a zwitterion forming copolymer. The thiolene click reaction successfully isolated the tertiary amine-modified zwitterion copolymer. Most importantly, the resulting membrane prepared from the click reaction had no unsaturated bonds from the allyl group or the corresponding isomer which makes it very stable at all conditions. Additionally, the resulting membrane exhibited a decent performance in terms of water flux $\left(2.5 \mathrm{~L} \cdot \mathrm{m}^{-2} \cdot \mathrm{h}^{-1}\right)$ and $\mathrm{NaCl}$ rejection above $98 \%$ even under high chlorine exposure. The hydration layer induced by the stabilized zwitterion copolymer successfully imparted antifouling capability to the membrane, granting a high flux recovery up to $94 \%$. Table 6 summarizes the recent works involved in click chemistry for desalination membrane modification.

Table 6. Summary of click chemistry for membrane modification.

\begin{tabular}{|c|c|c|c|c|c|c|c|}
\hline Application & Membrane & Click Approach & $\begin{array}{l}\text { Feed } \\
\text { Solution }\end{array}$ & $\begin{array}{l}\text { Water Flux } \\
\left(\mathrm{L} \cdot \mathrm{m}^{-2} \cdot \mathrm{h}^{-1}\right)\end{array}$ & $\begin{array}{l}\text { Salt } \\
\text { Rejection } \\
(\%)\end{array}$ & $\begin{array}{l}\text { Flux } \\
\text { Recovery } \\
(\%)\end{array}$ & Ref. \\
\hline NF & $\begin{array}{l}\text { Lbl PAA/PVA } \\
\text { ceramic } \\
\text { membrane }\end{array}$ & $\begin{array}{l}\text { Click reaction to } \\
\text { link PAA and } \\
\text { PVA layers }\end{array}$ & $1 \mathrm{~g} \cdot \mathrm{L}^{-1} \mathrm{NaCl}$ & $\sim 25.0$ & 3.0 & $\mathrm{~N} / \mathrm{A}$ & [131] \\
\hline NF & $\begin{array}{l}\text { Lbl PAA/PAH } \\
\text { PSU membrane }\end{array}$ & $\begin{array}{l}\text { Click reaction to } \\
\text { link PAA and } \\
\text { PAH layers }\end{array}$ & $\begin{array}{l}32 \mathrm{~g} \cdot \mathrm{L}^{-1} \\
\mathrm{NaCl} \\
2 \mathrm{~g} \cdot \mathrm{L}^{-1} \\
\mathrm{CaCl}_{2}\end{array}$ & $\sim 300.0$ & $\begin{array}{l}\sim 50(\mathrm{NaCl}) \\
\sim 80\left(\mathrm{CaCl}_{2}\right)\end{array}$ & $\mathrm{N} / \mathrm{A}$ & [130] \\
\hline $\mathrm{RO}$ & $\begin{array}{l}\text { Lbl PEG TFC } \\
\text { membrane }\end{array}$ & $\begin{array}{l}\text { Click reaction to } \\
\text { stabilize PEG } \\
\text { multilayers }\end{array}$ & $\begin{array}{l}30.83 \mathrm{~g} \cdot \mathrm{L}^{-1} \\
\mathrm{NaCl}\end{array}$ & $\sim 110.0$ & $>94.5$ & $\mathrm{~N} / \mathrm{A}$ & [127] \\
\hline $\mathrm{RO}$ & $\begin{array}{l}\text { SBAES } \\
\text { zwitterionic TFC } \\
\text { membrane }\end{array}$ & $\begin{array}{l}\text { Clicked post- } \\
\text { polymerization } \\
\text { for PAES } \\
\text { copolymer }\end{array}$ & $\begin{array}{l}2.0 \mathrm{~g} \cdot \mathrm{L}^{-1} \\
\mathrm{NaCl}\end{array}$ & 27.2 & $\sim 98$ & 94 & [129] \\
\hline $\mathrm{RO}$ & $\begin{array}{l}\text { Aquaporin-FBP } \\
\text { TFC membrane }\end{array}$ & $\begin{array}{l}\text { Click reaction to } \\
\text { link FBP and } \\
\text { PSU substrate }\end{array}$ & $\begin{array}{l}1.0 \mathrm{~g} \cdot \mathrm{L}^{-1} \\
\mathrm{NaCl}\end{array}$ & $\sim 4.53$ & 12.5 & $\mathrm{~N} / \mathrm{A}$ & [128] \\
\hline $\mathrm{FO}$ & $\begin{array}{l}\text { mPEG TFC } \\
\text { membrane }\end{array}$ & $\begin{array}{l}\text { Click reaction to } \\
\text { graft mPEG onto } \\
\text { PSU substrate }\end{array}$ & $\mathrm{NaCl}$ & $\sim 2.5$ & High & $\mathrm{N} / \mathrm{A}$ & [135] \\
\hline FO & $\begin{array}{l}\text { Ag-GO TFC } \\
\text { membrane }\end{array}$ & $\begin{array}{l}\text { Click reaction to } \\
\text { graft } \mathrm{Ag}-\mathrm{GO} \\
\text { onto PA layer }\end{array}$ & $50 \mathrm{mM} \mathrm{NaCl}$ & $\sim 5.5$ & $\sim 95$ & $\mathrm{~N} / \mathrm{A}$ & [136] \\
\hline FO & $\begin{array}{l}\text { PZs TFC } \\
\text { membrane }\end{array}$ & $\begin{array}{l}\text { Click reaction to } \\
\text { graft PZs onto } \\
\text { PA layer }\end{array}$ & $20 \mathrm{mM} \mathrm{NaCl}$ & $\sim 5.4$ & High & $\sim 100$ & [137] \\
\hline
\end{tabular}

\subsection{Chemical Vapor Deposition for Membrane Modification}

Chemical vapor deposition (CVD) is a chemical decomposition process whereby a vapor precursor is converted into solid material and coated onto a substrate surface upon heating [138]. There are many kinds of CVD processes, such as atmospheric pressure CVD, low pressure CVD, laser CVD, and plasma-enhanced CVD (PECVD) [139], as depicted in Figure 10. The energy required to initiate the polymerization process for CVD originates from various sources, such as plasma species for PECVD and laser for laser CVD [140,141]. The solid product is commonly in the form of thin film, single crystal or powder. Compared to many traditional methods, CVD is much more versatile as a wide range of chemical, physical, and even the tribological properties of materials can be produced by manipulating experimental conditions such as reaction gas mixture composition, total gas pressure, substrate temperature and substrate material. [138]. The other advantages of CVD include 
large area growth coverage, conformal growth, high reproducibility, and a high purity product [142]. Most importantly, the whole process does not require solvent, making it an environmentally friendly process.

(a)

\section{Pressure sensor}

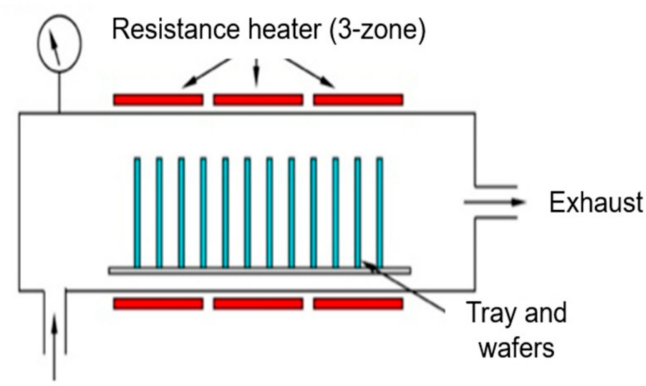

Gas inlet (b)

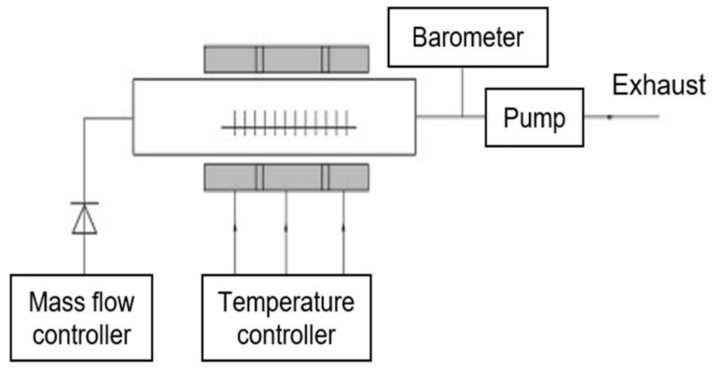

(c)

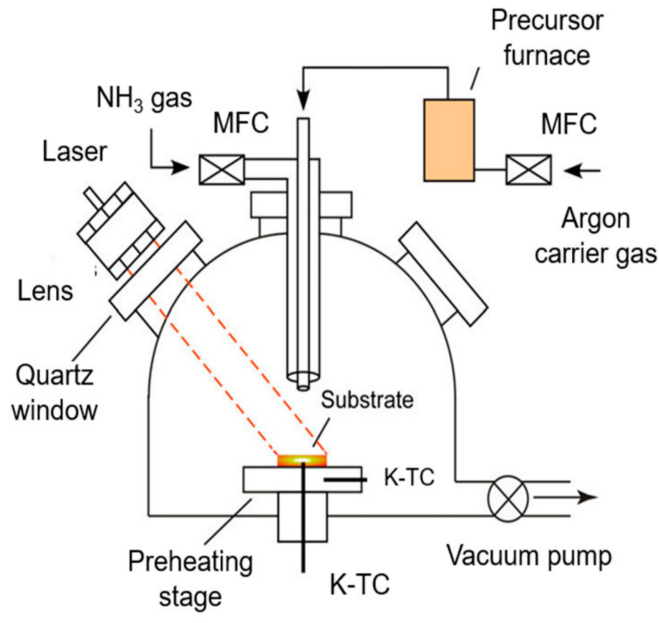

(d)

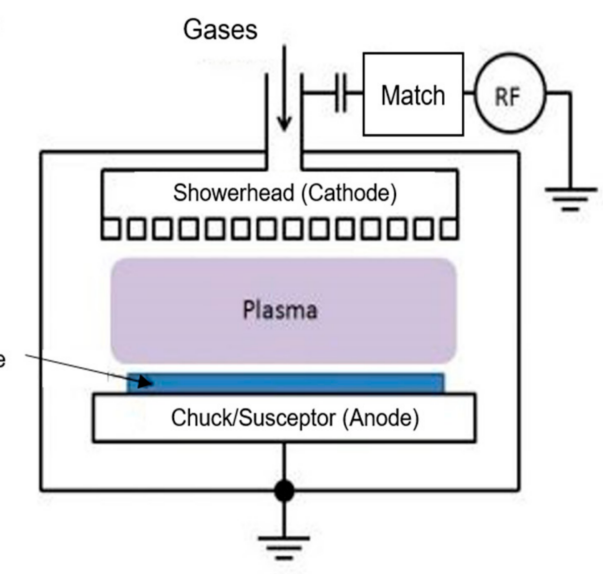

Figure 10. Configuration setup for (a) atmospheric chemical vapor deposition (CVD); (b) low pressure CVD; (c) laser CVD; and (d) plasma-enhanced CVD (PECVD) $[143,144]$.

To date, CVD has been widely used in thin film-related applications, as it can produce coating with uniform thickness and low porosity even on a substrate with a complicated shape [138]. Hence, its feasibility in membrane application has been investigated by some researchers. Among all the CVD processes, a novel method, namely initiated CVD (iCVD) has gained attraction, whereby the deposition of materials is completed via free-radical polymerization induced by gas phase radicals at low operating pressure and temperature without employing any solvent. Ozaydin-Ince et al. [145] used iCVD to coat the amphiphilic copolymer films of hydrophobic perfluorodecylacrylate (PFA) hydrophilic hydroxyethylmethacrylate on commercial RO membranes to cope with membrane biofouling, which is a prickly issue for TFC membrane. Using the iCVD technique, the membrane was modified without the active layer being damaged. An optimum composition of the copolymer films was experimented with and obtained to achieve a high membrane performance and reduce cells' attachment, with a coating thickness of $20 \mathrm{~nm}$ as the most optimum flux performance. Compared to the control of commercial membranes, the modified membranes with $20 \mathrm{~nm}$ coating had a $10 \%$ water flux lower owing to the additional layer, and even lower to $50 \%$ with $50 \mathrm{~nm}$ coating. The salt rejection was maintained at $98 \%$ for both coated and control membranes, which, however, was not affected by the coating chemistry. The rather insignificant flux drop was then compensated by a great improvement in the membrane 
antibiofouling performance, whereby the cell attachment on the surface of the modified membrane was greatly reduced after $1 \mathrm{~h}$ of experiment.

A similar outcome was observed by Matin et al. [146], where iCVD was employed to modify the surface of commercial RO membranes. 2-hydroxyethyl methacrylate-coperfluorodecyl acrylate (HEMA-co-PFDA) copolymer films was introduced to the membrane surface via iCVD for sodium alginate fouling reduction. The coated membrane exhibited a much lower water contact angle, indicating that hydrophilicity was imparted from the copolymer films. Moreover, the flux reduction in the modified membrane is much lower than the control membrane, while the salt rejection was nearly unaltered. Even though fouling appears to be an inevitable phenomenon in membrane process, however, it can be potentially delayed by iCVD surface modification. Kazemi et al. [147] prepared large area graphene membrane for desalination application. The graphene membrane was fabricated via CVD to control the porosity. CVD-grown graphene, however, possesses some inevitable characteristics such as intrinsic defect, cracked hole, and wrinkles which could impact the membrane performance adversely, hence hole arrays in silicon were employed as the secondary support. The resulting membrane exhibited decent water permeation and varied salt rejection $(58-100 \%)$. The highly varied salt rejections were attributed to the different array diameters and numbers. In short, the lower rejections were advantageous in terms of selectivity when dealing with solution containing multiple ions or bigger size ions granting high permeation, while the high rejections were ideal for water desalination.

On the other hand, Lai et al. [148] employed PECVD for the incorporation of poly (hexafluorobutyl acrylate)-modified hydrous manganese oxide (PHFBA-modified HMO) nanomaterials in TFN membrane for NF desalination. The polymerization reaction involves reactions between plasma species, surface and plasma species, and surface and surface species [149]. However, in this study, PECVD was not only served as a green approach for membrane modification, instead it was also effective in enhancing the dispersibility of HMO in solvent reducing agglomeration. The even dispersion of the modified HMO over the membrane surface led to remarkable water permeability enhancement, with $0.5 w / v \% \mathrm{HMO}$ as the optimum amount for the highest water permeability which was $66.6 \%$ higher than the control TFC. The modified HMO incorporation also significantly improved the membrane surface negativity and PA cross-linking degree, resulting in excellent salt rejections $\left(\mathrm{Na}_{2} \mathrm{SO}_{4}: 98.6 \% ; \mathrm{MgSO}_{4}: 97.6 \%\right)$. In addition, the resulting TFN membrane also exhibited remarkable fouling resistance improvement against organic and inorganic foulants.

\subsection{Plasma Treatment for Membrane Modification}

To improve the performance of membrane desalination, the incorporation of nanofillers plays a vital role as it undeniably grants certain desirable traits to the membrane such as permeability and selectivity. However, before it finally reaches the form where it can be highly desirable, there are always some unwanted paradox to deal with. For instance, most nanofillers have a natural tendency to agglomerate forming large clusters, further inducing stress in the membrane composite and degrading its properties [150,151]. Additionally, due to the possibly different physicochemical properties of nanofillers and polymer, it often results in poor compatibility between them. Therefore, nanofillers or membrane surface modification becomes an indispensable step before dispersing into the polymer matrix in order to fully minimize the agglomeration and improve the matrix compatibility.

Plasma treatment emerges as an effortless yet effective method to cope with this problem. Notably, the use of solvent is not needed throughout the process, making it a green method that fulfils the objective of this study. In brief, the plasma treatment creates a reactive environment which consists of radicals, electrons, ions, and excited molecules [152]. As soon as the interaction with a solid surface occurs, the process is complete right after the transfer of energy from the plasma particles through elastic and inelastic collisions which significantly induce physical and/or chemical changes in that surface. Plasma treatment is a versatile technique that can be applied for a wide range of materials such as polymer and 
inorganic nanomaterials. Since the performance of membrane separation such as water flux and rejection mainly depend on the size exclusion and membrane surface characteristics, the range of applications can be potentially improved via plasma treatment [153].

In a pioneering study by $\mathrm{Wu}$ et al. [154], the chlorine resistance and the water permeability of the prepared RO membrane was significantly improved by plasma treatment with oxygen and argon plasma at high discharge power. The oxygen plasma successfully introduced the carboxyl group to the membrane surface, increasing permeability while cross-linking induced by argon plasma at the nitrogen site of PA improved the membrane chlorine resistance. As commercial membranes often face difficulties in rejecting multivalent cations and specific ionic species owing to surface negativity, Déon et al. [155] grafted allylamine on commercial PA membrane using plasma treatment modification. The plasma-treated membrane possessed high selectivity for monovalent and divalent ions regardless of their charges, exhibiting excellent solutes rejection. The astonishing rejection performances and selectivity of the resulting membranes were caused by the partial coverage of poly(allylamine), whereby 5 and $10 \mathrm{~min}$ of polymerization yielded membranes with a slightly negative or slightly positive overall apparent zeta potential. Meanwhile, the water permeability was marginally affected by the plasma treatment, whereby the modified membrane experienced a $20 \%$ lower water permeability compared to the pristine membrane. This phenomenon was due to a decrease in membrane mean pore size by around $60 \%$ after plasma-assisted grafting.

On the other hand, Ohland et al. [156] functionalized hydroxyapatite (Hap) particles with argon plasma treatment to insert hydroxyl groups onto the surface and further incorporated into CA membrane. A huge leap of water permeability $\left(0.39-0.51 \mathrm{~L} \cdot \mathrm{h}^{-1} \cdot \mathrm{m}^{-2} \cdot \mathrm{bar}^{-1}\right)$ was achieved while maintaining a high level of $\mathrm{MgSO}_{4}$ and $\mathrm{NaCl}$ rejections in $\mathrm{RO}$ desalination system. When tested in the FO system, the water flux was also enhanced by $66 \%$ from 4.5 to $7.5 \mathrm{~L} \cdot \mathrm{h}^{-1} \cdot \mathrm{m}^{-2}$ with a low reverse salt flux consistently maintained. In short, it is safe to conclude that the plasma treatment and hydroxyl group insertion successfully improved the membrane hydrophilicity without adversely disrupting the membrane morphology. Woo et al. [157] fabricated an omniphobic PVDF membrane by electrospinning and plasma treatment with the $\mathrm{CF}_{4}$ plasma for air gap MD brine treatment. From the morphological studies, it was observed that the formation of new $\mathrm{CF}_{3}$ and $\mathrm{CF}_{2}-\mathrm{CF}_{2}$ bonds from the plasma treatment had successfully lowered the surface energy of the membrane granting omniphobic properties and wetting resistance. Regarding the performance tests, the resulting membrane exhibited stable normalized flux and great solute rejection even after adding $0.7 \mathrm{mM}$ of sodium dodecyl sulphate (SDS) to the brine feed as surfactant. The commercial PVDF membrane on the contrary, suffered from surface wetting after the addition of $0.3 \mathrm{mM}$ SDS.

\section{Future Challenges and Conclusions}

Although fresh water scarcity has become a gradually developing chronic issue in the world, the majority the people still have less concern and less awareness of this issue, preventing the development pace from catching up with the extent of severity. Membrane desalination as an emerging technology has great potential to overcome the water scarcity issue with high efficiency. However, the traditional membrane preparation methods usually involve the use of toxic solvents which carry the danger of eco-toxicity, hence replacing the traditional solvents with some non-toxic or less toxic solvents is highly desirable. It is not merely a suggestion but also a need to find greener alternatives to traditional solvents, as the European Union has started to restrict the use of toxic organic solvents in 2020. For instance, NMP usage cannot exceed a concentration of $0.3 \%$, excepting that both manufacturer and consumer parties are willing to undergo appropriate risk management protocols [61]. Obviously, other traditional solvents have a similar fate awaiting them. Soon, it is expected that the solvent restrictions will be imposed on every country in the world. Many of the industries involving solvents will be harshly affected. Nonetheless, switching to green solvents that complies with the regulation have some challenges to be 
overcome, mainly impaired performance and price competitiveness. Specifically in the membrane industry, it is difficult to find solvents which produce membranes with on par performance with those prepared using well-established solvents like NMP. Some green solvents might give a similar performance to the traditional ones, yet the production routes are still costly, such as ionic liquids. In fact, there are reasons why traditional solvents have been widely employed until today despite their well-known toxicity, because they simply offer more advantages compared to the greener alternatives: particularly, unproducible in the large scale, limited dissolution, limited production area, high viscosity, and high cost. Fortunately, results from some research gave indication that it is completely possible to achieve these goals simultaneously, not yet now but very soon. In the future, it is expected that more concerted efforts will be done by the research and scientific communities to overcome these obstacles, while the solvent selection trend will be either inclined towards extracting bio-solvent from the nature such as plants or animals which is completely non-toxic, or the solvent-free approach as the ultimate green goal.

Meanwhile, membrane modification which produces harmful by-products can be minimized by using solvent-free techniques such as CVD or plasma treatment, or utilizing click chemistry reaction which is mostly performed in non-stringent conditions without consuming much external energy and producing an inoffensive bi-product. A challenge faced is the inability of CVD to produce large area defect-free materials such as large area graphene sheets, which are in high demand but not commercially available yet in the market. Then, it creates new prospects and insights in developing the growth of large-area high-quality defect-free materials with desired traits, such as excellent dispersion, welldefined sizes and fine control on layer thickness in the future. Meanwhile, in click-chemistry, despite being all good in terms of the green approach with great efficiency, optimization is still required to overcome certain challenges such as the alkyne homocoupling, whereby alkyne reacts with other alkyne groups instead of the azide group. Some click reactions require a metal catalyst such as copper to avoid producing by-products, and long-term exposure to the metal could lead to physiological side effects such as neurologic and renal diseases. Hence, in the future, it is expected to discover more reaction routes such as the substitution of the azide group with other less hazardous species.

In a nutshell, although membrane processes are recognized as green processes, traditional membrane fabrication methods are rather hazardous due to the toxic solvents employed throughout the fabrication steps such as phase inversion, membrane modification, and post-treatment. With the lead of green chemistry principles which advocate the use of materials with low environmental impacts, it is definitely possible to prepare the desalination membrane of desired morphologies and performances in a much more sustainable approach. Particularly, during phase inversion, non-toxic solvents categorized into organic synthetic solvents, bio-sourced solvents, and ionic liquids are used to replace the traditional ones with high toxicity. Nevertheless, it is important to know that while environmental advantages alone are not sufficient for the widespread adoption of green solvents, factors like performances and costs also make their counts. While for membrane modification processes, the employment of solvent-free techniques such as click reaction, CVD or plasma treatment are greatly encouraged. The ease of these techniques creates new insight for the maximum production and efficacy of membranes with minimum environmental impacts. With more works being published, the era of membrane technologies is shifting towards sustainability. In the future, the consideration of sustainability will definitely be one of the criteria for judging membrane performances.

Funding: This research was funded by the Ministry of Education, Fundamental Research Grant Scheme (FRGS) FRGS/1/2018/STG07/UTM/02/17 and Tamkeen NYUAD Research Institute Award (Project CG007).

Institutional Review Board Statement: Not applicable.

Informed Consent Statement: Not applicable. 
Data Availability Statement: Not applicable.

Acknowledgments: The authors would like to acknowledge the financial supports provided by Ministry of Higher Education under Fundamental Research Grant Scheme (FRGS) FRGS/1/2018/STG07/ UTM/02/17 and research management supports provided by Universiti Teknologi Malaysia. Nidal Hilal thanks Tamkeen for supporting the NYUAD Water Research Center under the NYUAD Research Institute Award (project CG007).

Conflicts of Interest: The authors declare no conflict of interest.

\begin{tabular}{|c|c|}
\hline MSF & Multi-stage flash \\
\hline $\mathrm{RO}$ & Reverse osmosis \\
\hline MED & Multi-effect distillation \\
\hline NF & Nanofiltration \\
\hline FS & Feed solution \\
\hline MD & Membrane distillation \\
\hline $\mathrm{FO}$ & Forward osmosis \\
\hline DS & Draw solution \\
\hline UF & Ultration filtration \\
\hline TFC & Thin film composite \\
\hline IP & Interfacial polymerization \\
\hline NMP & $N$-methyl-2-pyrrolidone \\
\hline DMA & $N, N$-dimethylacetamide \\
\hline DMF & $N, N$-dimethylformamide \\
\hline THF & Tetrahydrofuran \\
\hline TIPS & Temperature-induced phase separation \\
\hline NIPS & Non-solvent induced phase separation \\
\hline EIPS & Evaporation-induced phase inversion \\
\hline VIPS & Vapor-induced phase inversion \\
\hline DMSO & Dimethyl sulfoxide \\
\hline АТВС & Acetyltributylcitrate \\
\hline ATEC & Acetyltriethylcitrate \\
\hline HSP & Hansen solubility parameter \\
\hline VOC & Volatile organic compounds \\
\hline $\mathrm{CNCs}$ & Cellulose nanocrystals \\
\hline CTA & Cellulose triacetate \\
\hline PA & Polyamide \\
\hline ANF & Kevlar aramid nanofiber \\
\hline DMC & Dimethyl carbonate \\
\hline PVDF-HFP & Poly(vinylidene fluoride-hexafluoropropylene) \\
\hline DCMD & Direct contact membrane distillation \\
\hline MWCO & Molecular weight cut off \\
\hline DOP & Dioctyl phthalate \\
\hline PEEK-WC & Polyether ether ketone \\
\hline HFMC & Hollow fiber membrane contractor \\
\hline ECTFE & Poly(ethylene chlorotrifluoroethylene) \\
\hline DEP & Diethyl phthalate \\
\hline PBI & Polybenzimidazole \\
\hline$([\mathrm{EMIM}] \mathrm{OAc})$ & 1-ethyl-3-methylimidazolium acetate \\
\hline GTA & Glycerol triacetate \\
\hline ICP & Internal concentration polarization \\
\hline Lbl & Layer-by-layer \\
\hline PEG & Polyethylene glycol \\
\hline PAH & Polyallylamine hydrochloride \\
\hline PAA & Polyacrylic acid \\
\hline
\end{tabular}




$\begin{array}{ll}\text { GA } & \text { Glutaraldehyde } \\ \text { TFN } & \text { Thin film nanocomposite } \\ \text { FBP } & \text { Functionalized } \beta \text {-sheet peptide } \\ \text { mPEG } & \text { Methoxypolyethylene glycol } \\ \text { PZs } & \text { Polyzwitterions } \\ \text { GO } & \text { Graphene oxide } \\ \text { CVD } & \text { Chemical vapor deposition } \\ \text { PECVD } & \text { Plasma-enhanced chemical vapor deposition } \\ \text { iCVD } & \text { Initiated chemical vapor deposition } \\ \text { PFA } & \text { Perfluorodecylacrylate } \\ \text { HEMA-co-PFDA } & \text { 2-hydroxyethyl methacrylate-co-perfluorodecyl acrylate } \\ \text { PHFBA-modified HMO } & \text { Poly (hexafluorobutyl acrylate)-modified hydrous manganese oxide } \\ \text { Hap } & \text { Hydroxyapatite }\end{array}$

\section{References}

1. Ahmad, N.A.; Goh, P.S.; Yogarathinam, L.T.; Zulhairun, A.K.; Ismail, A.F. Current advances in membrane technologies for produced water desalination. Desalination 2020, 493. [CrossRef]

2. Lee, W.J.; Ng, Z.C.; Hubadillah, S.K.; Goh, P.S.; Lau, W.J.; Othman, M.H.D.; Ismail, A.F.; Hilal, N. Fouling mitigation in forward osmosis and membrane distillation for desalination. Desalination 2020, 480, 114338. [CrossRef]

3. Jones, E.; Qadir, M.; van Vliet, M.T.H.; Smakhtin, V.; Kang, S.M. The state of desalination and brine production: A global outlook. Sci. Total Environ. 2019, 657, 1343-1356. [CrossRef]

4. Van der Bruggen, B. Desalination by distillation and by reverse osmosis—trends towards the future. Membr. Technol. 2003, 2003, 6-9. [CrossRef]

5. Youssef, P.G.; Al-Dadah, R.K.; Mahmoud, S.M. Comparative analysis of desalination technologies. Energy Procedia 2014, 61, 2604-2607. [CrossRef]

6. Wang, Q.; Li, N.; Bolto, B.; Hoang, M.; Xie, Z. Desalination by pervaporation: A review. Desalination 2016, 387, 46-60. [CrossRef]

7. Takabatake, H.; Taniguchi, M.; Kurihara, M. Advanced technologies for stabilization and high performance of seawater ro membrane desalination plants. Membranes 2021, 11, 138. [CrossRef]

8. Curto, D.; Franzitta, V.; Guercio, A. A review of the water desalination technologies. Appl. Sci. 2021, 11, 670. [CrossRef]

9. Charcosset, C. A review of membrane processes and renewable energies for desalination. Desalination 2009, $245,214-231$. [CrossRef]

10. García-Rodríguez, L. Renewable energy applications in desalination: State of the art. Sol. Energy 2003, 75, 381-393. [CrossRef]

11. Drioli, E.; Fontananova, E. Membrane materials for addressing energy and environmental challenges. Annu. Rev. Chem. Biomol. Eng. 2012, 3, 395-420. [CrossRef]

12. Mohammad, A.W.; Hilal, N.; Al-Zoubi, H.; Darwish, N.A. Prediction of permeate fluxes and rejections of highly concentrated salts in nanofiltration membranes. J. Membr. Sci. 2007, 289, 40-50. [CrossRef]

13. Liu, Y.; Wang, J.; Wang, L. An energy-saving "nanofiltration/electrodialysis with polarity reversal (NF/EDR)" integrated membrane process for seawater desalination. Part III. Optimization of the energy consumption in a demonstration operation. Desalination 2019, 452, 230-237. [CrossRef]

14. Alsarayreh, A.A.; Al-Obaidi, M.A.; Al-Hroub, A.M.; Patel, R.; Mujtaba, I.M. Evaluation and minimisation of energy consumption in a medium-scale reverse osmosis brackish water desalination plant. J. Clean. Prod. 2020, 248, 119220. [CrossRef]

15. Al-Karaghouli, A.; Kazmerski, L.L. Energy consumption and water production cost of conventional and renewable-energypowered desalination processes. Renew. Sustain. Energy Rev. 2013, 24, 343-356. [CrossRef]

16. Elimelech, M.; Phillip, W. The future of seawater desalination: Energy, technology, and the environment. Science 2011, 333, 712-717. [CrossRef] [PubMed]

17. Mayor, B. Growth patterns in mature desalination technologies and analogies with the energy field. Desalination 2019, 457, 75-84. [CrossRef]

18. Khawaji, A.D.; Kutubkhanah, I.K.; Wie, J.M. Advances in seawater desalination technologies. Desalination 2008, 221, 47-69. [CrossRef]

19. Greenlee, L.F.; Lawler, D.F.; Freeman, B.D.; Marrot, B.; Moulin, P. Reverse osmosis desalination: Water sources, technology, and today's challenges. Water Res. 2009, 43, 2317-2348. [CrossRef] [PubMed]

20. Lee, W.J.; Goh, P.S.; Lau, W.J.; Ong, C.S.; Ismail, A.F. Antifouling zwitterion embedded forward osmosis thin film composite membrane for highly concentrated oily wastewater treatment. Sep. Purif. Technol. 2019, 214, 40-50. [CrossRef]

21. Anis, S.F.; Hashaikeh, R.; Hilal, N. Reverse osmosis pretreatment technologies and future trends: A comprehensive review. Desalination 2019, 452, 159-195. [CrossRef]

22. Altaee, A.; Hilal, N. High recovery rate NF-FO-RO hybrid system for inland brackish water treatment. Desalination 2015, 363, 19-25. [CrossRef]

23. Lalia, B.S.; Kochkodan, V.; Hashaikeh, R.; Hilal, N. A review on membrane fabrication: Structure, properties and performance relationship. Desalination 2013, 326, 77-95. [CrossRef] 
24. Figoli, A.; Marino, T.; Simone, S.; Di Nicolò, E.; Li, X.M.; He, T.; Tornaghi, S.; Drioli, E. Towards non-toxic solvents for membrane preparation: A review. Gr. Chem. 2014, 16, 4034-4059. [CrossRef]

25. Thomas, R.; Guillen-Burrieza, E.; Arafat, H.A. Pore structure control of PVDF membranes using a 2-stage coagulation bath phase inversion process for application in membrane distillation (MD). J. Membr. Sci. 2014, 452, 470-480. [CrossRef]

26. Liu, M.; Chen, D.G.; Xu, Z.L.; Wei, Y.M.; Tong, M. Effects of nucleating agents on the morphologies and performances of poly(vinylidene fluoride) microporous membranes via thermally induced phase separation. J. Appl. Polym. Sci. 2013, 128, 836-844. [CrossRef]

27. Alsebaeai, M.K.; Ahmad, A.L. Membrane distillation: Progress in the improvement of dedicated membranes for enhanced hydrophobicity and desalination performance. J. Ind. Eng. Chem. 2020, 86, 13-34. [CrossRef]

28. Kim, D.; Nunes, S.P. Green solvents for membrane manufacture: Recent trends and perspectives. Curr. Opin. Gr. Sustain. Chem. 2021, 28, 100427. [CrossRef]

29. Lawler, W.; Bradford-Hartke, Z.; Cran, M.J.; Duke, M.; Leslie, G.; Ladewig, B.P.; Le-Clech, P. Towards new opportunities for reuse, recycling and disposal of used reverse osmosis membranes. Desalination 2012, 299, 103-112. [CrossRef]

30. Xia, B.; Ding, T.; Xiao, J. Life cycle assessment of concrete structures with reuse and recycling strategies: A novel framework and case study. Waste Manag. 2020, 105, 268-278. [CrossRef]

31. Elsaid, K.; Sayed, E.T.; Abdelkareem, M.A.; Mahmoud, M.S.; Ramadan, M.; Olabi, A.G. Environmental impact of emerging desalination technologies: A preliminary evaluation. J. Environ. Chem. Eng. 2020, 8, 104099. [CrossRef]

32. Kim, J. Recent Progress on Improving the Sustainability of Membrane Fabrication. J. Membr. Sci. Res. 2019. [CrossRef]

33. Singh, M.; Haring, A.P.; Tong, Y.; Cesewski, E.; Ball, E.; Jasper, R.; Davis, E.M.; Johnson, B.N. Additive manufacturing of mechanically isotropic thin films and membranes via microextrusion 3D printing of polymer solutions. ACS Appl. Mater. Interfaces 2019, 11, 6652-6661. [CrossRef]

34. Dommati, H.; Ray, S.S.; Wang, J.C.; Chen, S.S. A comprehensive review of recent developments in 3D printing technique for ceramic membrane fabrication for water purification. RSC Adv. 2019, 9, 16869-16883. [CrossRef]

35. Sapalidis, A.A. Porous Polyvinyl alcohol membranes: Preparation methods and applications. Symmetry 2020, 12, 960. [CrossRef]

36. Strathmann, H.; Kock, K. The formation mechanism of phase inversion membranes. Desalination 1977, 21, 241-255. [CrossRef]

37. Zare, S.; Kargari, A. 4-Membrane properties in membrane distillation. In Emerging Technologies for Sustainable Desalination Handbook; Gude, V.G., Ed.; Butterworth-Heinemann: Oxford, UK, 2018; pp. 107-156. [CrossRef]

38. Yang, L.; Wang, Z.; Zhang, J.; Song, P.; Liu, L. TIPS-co-NIPS method to prepare PES substrate with enhanced permeability for TFC-FO membrane. J. Taiwan Instit. Chem. Eng. 2017, 80, 137-148. [CrossRef]

39. Simone, S.; Figoli, A.; Santoro, S.; Galiano, F.; Alfadul, S.M.; Al-Harbi, O.A.; Drioli, E. Preparation and characterization of ECTFE solvent resistant membranes and their application in pervaporation of toluene/water mixtures. Sep. Purif. Technol. 2012, 90, 147-161. [CrossRef]

40. M’barki, O.; Hanafia, A.; Bouyer, D.; Faur, C.; Sescousse, R.; Delabre, U.; Blot, C.; Guenoun, P.; Deratani, A.; Quemener, D.; et al. Greener method to prepare porous polymer membranes by combining thermally induced phase separation and crosslinking of poly(vinyl alcohol) in water. J. Membr. Sci. 2014, 458, 225-235. [CrossRef]

41. Zhang, H.; Lu, X.; Liu, Z.; Ma, Z.; Wu, S.; Li, Z.; Kong, X.; Wu, C. Study of the dual role mechanism of water-soluble additive in low temperature thermally-induced phase separation. J. Membr. Sci. 2017, 543, 1-9. [CrossRef]

42. Gu, M.; Zhang, J.; Wang, X.-L.; Ma, W. Crystallization behavior of PVDF in PVDF-DMP system via thermally induced phase separation. J. Appl. Polym. Sci. 2006, 102, 3714-3719. [CrossRef]

43. Cui, Z.Y.; Du, C.H.; Xu, Y.Y.; Ji, G.L.; Zhu, B.K. Preparation of porous PVdF membrane via thermally induced phase separation using sulfolane. J. Appl. Polym. Sci. 2008, 108, 272-280. [CrossRef]

44. Lin, Y.; Tang, Y.; Ma, H.; Yang, J.; Tian, Y.; Ma, W.; Wang, X.-L. Formation of a bicontinuous structure membrane of polyvinylidene fluoride in diphenyl carbonate diluent via thermally induced phase separation. J. Appl. Polym. Sci. 2009, 114, 1523-1528. [CrossRef]

45. Simone, S.; Figoli, A.; Criscuoli, A.; Carnevale, M.C.; Rosselli, A.; Drioli, E. Preparation of hollow fibre membranes from PVDF/PVP blends and their application in VMD. J. Membr. Sci. 2010, 364, 219-232. [CrossRef]

46. Figoli, A.; Simone, S.; Criscuoli, A.; Al-Jlil, S.A.; Al Shabouna, F.S.; Al-Romaih, H.S.; Di Nicolò, E.; Al-Harbi, O.A.; Drioli, E. Hollow fibers for seawater desalination from blends of PVDF with different molecular weights: Morphology, properties and VMD performance. Polymer 2014, 55, 1296-1306. [CrossRef]

47. Kahrs, C.; Schwellenbach, J. Membrane formation via non-solvent induced phase separation using sustainable solvents: A comparative study. Polymer 2020, 186, 122071. [CrossRef]

48. Ma, W.; Chen, S.; Zhang, J.; Wang, X. Kinetics of thermally induced phase separation in the PVDF Blend/Methyl Salicylate system and its effect on membrane structures. J. Macromol. Sci. 2010, 50,1-15. [CrossRef]

49. Ramaswamy, S.; Greenberg, A.R.; Krantz, W.B. Fabrication of poly (ECTFE) membranes via thermally induced phase separation. J. Membr. Sci. 2002, 210, 175-180. [CrossRef]

50. Murthy, T.E.G.K.; Kishore, V.S. Effect of casting solvent and polymer on permeability of propranolol hydrochloride through membrane controlled transdermal drug delivery system. Indian J. Pharm. Sci. 2007, 69. [CrossRef]

51. Yave, W.; Quijada, R.; Ulbricht, M.; Benavente, R. Syndiotactic polypropylene as potential material for the preparation of porous membranes via thermally induced phase separation (TIPS) process. Polymer 2005, 46, 11582-11590. [CrossRef] 
52. Yang, Z.; Li, P.; Chang, H.; Wang, S. Effect of Diluent on the Morphology and Performance of IPP Hollow Fiber Microporous Membrane via Thermally Induced Phase Separation1 1Supported by the National Natural Science Foundation of China (No.20236030). Chin. J. Chem. Eng. 2006, 14, 394-397. [CrossRef]

53. Russo, F.; Galiano, F.; Pedace, F.; Aricò, F.; Figoli, A. Dimethyl isosorbide as a green solvent for sustainable ultrafiltration and microfiltration membrane preparation. ACS Sustain. Chem. Eng. 2020, 8, 659-668. [CrossRef]

54. Clarke, C.J.; Tu, W.C.; Levers, O.; Bröhl, A.; Hallett, J.P. Green and Sustainable Solvents in Chemical Processes. Chem. Rev. 2018, 118, 747-800. [CrossRef]

55. Razali, M.; Kim, J.F.; Attfield, M.; Budd, P.M.; Drioli, E.; Lee, Y.M.; Szekely, G. Sustainable wastewater treatment and recycling in membrane manufacturing. Gr. Chem. 2015, 17, 5196-5205. [CrossRef]

56. Amelio, A.; Genduso, G.; Vreysen, S.; Luis, P.; Van der Bruggen, B. Guidelines based on life cycle assessment for solvent selection during the process design and evaluation of treatment alternatives. Gr. Chem. 2014, 16, 3045-3063. [CrossRef]

57. Capello, C.; Fischer, U.; Hungerbühler, K. What is a green solvent? A comprehensive framework for the environmental assessment of solvents. Gr. Chem. 2007, 9, 927-934. [CrossRef]

58. Kamp, J.; Emonds, S.; Borowec, J.; Restrepo Toro, M.A.; Wessling, M. On the organic solvent free preparation of ultrafiltration and nanofiltration membranes using polyelectrolyte complexation in an all aqueous phase inversion process. J. Membr. Sci. 2021, 618, 118632. [CrossRef]

59. Medina-Gonzalez, Y.; Aimar, P.; Lahitte, J.F.; Remigy, J.C. Towards green membranes: Preparation of cellulose acetate ultrafiltration membranes using methyl lactate as a biosolvent. Int. J. Sustain. Eng. 2011, 4, 75-83. [CrossRef]

60. Rasool, M.A.; Pescarmona, P.P.; Vankelecom, I.F.J. Applicability of Organic Carbonates as Green Solvents for Membrane Preparation. ACS Sustain. Chem. Eng. 2019, 7, 13774-13785. [CrossRef]

61. Xie, W.; Li, T.; Tiraferri, A.; Drioli, E.; Figoli, A.; Crittenden, J.C.; Liu, B. Toward the Next Generation of Sustainable Membranes from Green Chemistry Principles. ACS Sustain. Chem. Eng. 2021, 9, 50-75. [CrossRef]

62. Hansen, C. Hansen Solubility Parameters: A User's Handbook, 2nd ed.; CRC Press: Boca Raton, FL, USA, 2007; pp. 546, 2012. [CrossRef]

63. Jung, J.T.; Kim, J.F.; Wang, H.H.; di Nicolo, E.; Drioli, E.; Lee, Y.M. Understanding the non-solvent induced phase separation (NIPS) effect during the fabrication of microporous PVDF membranes via thermally induced phase separation (TIPS). J. Membr. Sci. 2016, 514, 250-263. [CrossRef]

64. Fang, C.; Jeon, S.; Rajabzadeh, S.; Cheng, L.; Fang, L.; Matsuyama, H. Tailoring the surface pore size of hollow fiber membranes in the TIPS process. J. Mater. Chem. 2018, 6, 535-547. [CrossRef]

65. Sawada, S.I.; Ursino, C.; Galiano, F.; Simone, S.; Drioli, E.; Figoli, A. Effect of citrate-based non-toxic solvents on poly(vinylidene fluoride) membrane preparation via thermally induced phase separation. J. Membr. Sci. 2015, 493, 232-242. [CrossRef]

66. Cui, Z.; Hassankiadeh, N.T.; Lee, S.Y.; Woo, K.T.; Lee, J.M.; Sanguineti, A.; Arcella, V.; Lee, Y.M.; Drioli, E. Tailoring novel fibrillar morphologies in poly(vinylidene fluoride) membranes using a low toxic triethylene glycol diacetate (TEGDA) diluent. J. Membr. Sci. 2015, 473, 128-136. [CrossRef]

67. Sherwood, J.; De bruyn, M.; Constantinou, A.; Moity, L.; McElroy, C.R.; Farmer, T.J.; Duncan, T.; Raverty, W.; Hunt, A.J.; Clark, J.H. Dihydrolevoglucosenone (Cyrene) as a bio-based alternative for dipolar aprotic solvents. Chem. Commun. 2014, 50, 9650-9652. [CrossRef]

68. Marino, T.; Russo, F.; Criscuoli, A.; Figoli, A. TamiSolve ${ }^{\circledR N} \mathrm{NG}$ as novel solvent for polymeric membrane preparation. J. Membr. Sci. 2017, 542, 418-429. [CrossRef]

69. Rasool, M.A.; Van Goethem, C.; Vankelecom, I.F.J. Green preparation process using methyl lactate for cellulose-acetate-based nanofiltration membranes. Sep. Purif. Technol. 2020, 232, 115903. [CrossRef]

70. Xie, W.; Li, T.; Chen, C.; Wu, H.; Liang, S.; Chang, H.; Liu, B.; Drioli, E.; Wang, Q.; Crittenden, J.C. Using the green solvent dimethyl sulfoxide to replace traditional solvents partly and fabricating PVC/PVC-g-PEGMA blended ultrafiltration membranes with high permeability and rejection. Ind. Eng. Chem. Res. 2019, 58, 6413-6423. [CrossRef]

71. Chang, J.; Zuo, J.; Zhang, L.; O’Brien, G.S.; Chung, T.-S. Using green solvent, triethyl phosphate (TEP), to fabricate highly porous PVDF hollow fiber membranes for membrane distillation. J. Membr. Sci. 2017, 539, 295-304. [CrossRef]

72. Zheng, M.; Chen, J.; Chen, G.; Farajtabar, A.; Zhao, H. Solubility modelling and solvent effect for domperidone in twelve green solvents. J. Mol. Liq. 2018, 261, 50-56. [CrossRef]

73. Marino, T.; Galiano, F.; Simone, S.; Figoli, A. DMSO EVOL ${ }^{\mathrm{TM}}$ as novel non-toxic solvent for polyethersulfone membrane preparation. Environ. Sci. Pollut. Res. 2019, 26, 14774-14785. [CrossRef]

74. Prihatiningtyas, I.; Li, Y.; Hartanto, Y.; Vananroye, A.; Coenen, N.; Van der Bruggen, B. Effect of solvent on the morphology and performance of cellulose triacetate membrane/cellulose nanocrystal nanocomposite pervaporation desalination membranes. Chem. Eng. J. 2020, 388, 124216. [CrossRef]

75. Prihatiningtyas, I.; Gebreslase, G.A.; Van der Bruggen, B. Incorporation of Al2O3 into cellulose triacetate membranes to enhance the performance of pervaporation for desalination of hypersaline solutions. Desalination 2020, 474, 114198. [CrossRef]

76. Li, Y.; Wong, E.; Mai, Z.; Van der Bruggen, B. Fabrication of composite polyamide/Kevlar aramid nanofiber nanofiltration membranes with high permselectivity in water desalination. J. Membr. Sci. 2019, 592, 117396. [CrossRef]

77. Wang, Q.; Wang, Z.; Wu, Z. Effects of solvent compositions on physicochemical properties and anti-fouling ability of PVDF microfiltration membranes for wastewater treatment. Desalination 2012, 297, 79-86. [CrossRef] 
78. Adams, F.V.; Nxumalo, E.N.; Krause, R.W.M.; Hoek, E.M.V.; Mamba, B.B. The influence of solvent properties on the performance of polysulfone/ $\beta$-cyclodextrin polyurethane mixed-matrix membranes. J. Appl. Polym. Sci. 2013, 130, 2005-2014. [CrossRef]

79. Şener, T.; Okumuş, E.; Gürkan, T.; Yilmaz, L. The effect of different solvents on the performance of zeolite-filled composite pervaporation membranes. Desalination 2010, 261, 181-185. [CrossRef]

80. Shi, M.; Yan, W.; Zhou, Y.; Wang, Z.; Liu, L.; Zhao, S.; Ji, Y.; Wang, J.; Gao, C.; Zhang, P.; et al. Combining tannic acid-modified support and a green co-solvent for high performance reverse osmosis membranes. J. Membr. Sci. 2020, 595, 117474. [CrossRef]

81. Murillo, B.; de la Iglesia, Ó.; Rubio, C.; Coronas, J.; Téllez, C. Conversion of sugars to methyl lactate with exfoliated layered stannosilicate UZAR-S4. Catal. Today 2021, 362, 90-96. [CrossRef]

82. Lafreniere, L.Y.; Talbot, F.D.F.; Matsuura, T.; Sourirajan, S. Effect of poly(vinylpyrrolidone) additive on the performance of poly(ether sulfone) ultrafiltration membranes. Ind. Eng. Chem. Res. 1987, 26, 2385-2389. [CrossRef]

83. Abdoul Raguime, J.; Arthanareeswaran, G.; Thanikaivelan, P.; Mohan, D.; Raajenthiren, M. Performance characterization of cellulose acetate and poly(vinylpyrrolidone) blend membranes. J. Appl. Polym. Sci. 2007, 104, 3042-3049. [CrossRef]

84. Song, Z.; Xing, M.; Zhang, J.; Li, B.; Wang, S. Determination of phase diagram of a ternary PVDF/ $\gamma$-BL/DOP system in TIPS process and its application in preparing hollow fiber membranes for membrane distillation. Sep. Purif. Technol. 2012, 90, 221-230. [CrossRef]

85. Bey, S.; Criscuoli, A.; Simone, S.; Figoli, A.; Benamor, M.; Drioli, E. Hydrophilic PEEK-WC hollow fibre membrane contactors for chromium (Vi) removal. Desalination 2011, 283, 16-24. [CrossRef]

86. Coltelli, M.B.; Maggiore, I.D.; Bertoldo, M.; Signori, F.; Bronco, S.; Ciardelli, F. Poly(lactic acid) properties as a consequence of poly(butylene adipate-co-terephthalate) blending and acetyl tributyl citrate plasticization. J. Appl. Polym. Sci. 2008, 110, 1250-1262. [CrossRef]

87. Finkelstein, M.; Gold, H. Toxicology of the citric acid esters: Tributyl citrate, acetyl tributyl citrate, triethyl citrate, and acetyl triethyl citrate. Toxicol. Appl. Pharmacol. 1959, 1, 283-298. [CrossRef]

88. Cui, Z.; Hassankiadeh, N.T.; Lee, S.Y.; Lee, J.M.; Woo, K.T.; Sanguineti, A.; Arcella, V.; Lee, Y.M.; Drioli, E. Poly(vinylidene fluoride) membrane preparation with an environmental diluent via thermally induced phase separation. J. Membr. Sci. 2013, 444, 223-236. [CrossRef]

89. Hassankiadeh, N.T.; Cui, Z.; Kim, J.H.; Shin, D.W.; Sanguineti, A.; Arcella, V.; Lee, Y.M.; Drioli, E. PVDF hollow fiber membranes prepared from green diluent via thermally induced phase separation: Effect of PVDF molecular weight. J. Membr. Sci. 2014, 471, 237-246. [CrossRef]

90. Xu, K.; Cai, Y.; Hassankiadeh, N.T.; Cheng, Y.; Li, X.; Wang, X.; Wang, Z.; Drioli, E.; Cui, Z. ECTFE membrane fabrication via TIPS method using ATBC diluent for vacuum membrane distillation. Desalination 2019, 456, 13-22. [CrossRef]

91. Karkhanechi, H.; Rajabzadeh, S.; Di Nicolò, E.; Usuda, H.; Shaikh, A.R.; Matsuyama, H. Preparation and characterization of ECTFE hollow fiber membranes via thermally induced phase separation (TIPS). Polymer 2016, 97, 515-524. [CrossRef]

92. Wilson, R.F. Soybean: Market Driven Research Needs. In Genetics and Genomics of Soybean; Stacey, G., Ed.; Springer: New York, NY, USA, 2008; pp. 3-15.

93. Wiese, K.; Snyder, H. Analysis of the oil extraction process in soybeans: A new continuous procedure. J. AOCS 1987, $64,402-406$. [CrossRef]

94. Bin Latheef, M. Pulsed Ultrasound-Assisted Solvent Extraction of Oil From Soybeans and Microalgae. Master's Thesis, McGill University, Montreal, QC, Canada, 2012.

95. Tang, N.; Jia, Q.; Zhang, H.; Li, J.; Cao, S. Preparation and morphological characterization of narrow pore size distributed polypropylene hydrophobic membranes for vacuum membrane distillation via thermally induced phase separation. Desalination 2010, 256, 27-36. [CrossRef]

96. Wang, Y.J.; Zhao, Z.P.; Xi, Z.Y.; Yan, S.Y. Microporous polypropylene membrane prepared via TIPS using environment-friendly binary diluents and its VMD performance. J. Membr. Sci. 2018, 548, 332-344. [CrossRef]

97. Hulsbosch, J.; De Vos, D.E.; Binnemans, K.; Ameloot, R. Biobased ionic liquids: Solvents for a green processing industry? ACS Sustain. Chem. Eng. 2016, 4, 2917-2931. [CrossRef]

98. Eftekhari, A.; Saito, T. Synthesis and properties of polymerized ionic liquids. Eur. Polym. J. 2017, 90, 245-272. [CrossRef]

99. Li, Y.; Sniekers, J.; Malaquias, J.; Li, X.; Schaltin, S.; Stappers, L.; Binnemans, K.; Fransaer, J.; Vankelecom, I.F.J. A non-aqueous all-copper redox flow battery with highly soluble active species. Electrochim. Acta 2017, 236, 116-121. [CrossRef]

100. Maciel, V.G.; Wales, D.J.; Seferin, M.; Ugaya, C.M.L.; Sans, V. State-of-the-art and limitations in the life cycle assessment of ionic liquids. J. Clean. Prod. 2019, 217, 844-858. [CrossRef]

101. Szalaty, T.J.; Klapiszewski, Ł.; Jesionowski, T. Recent developments in modification of lignin using ionic liquids for the fabrication of advanced materials-A review. J. Mol. Liq. 2020, 301, 112417. [CrossRef]

102. Thuy Pham, T.P.; Cho, C.-W.; Yun, Y.-S. Environmental fate and toxicity of ionic liquids: A review. Water Res. 2010, 44, 352-372. [CrossRef]

103. Xing, D.Y.; Chan, S.Y.; Chung, T.S. The ionic liquid [EMIM]OAc as a solvent to fabricate stable polybenzimidazole membranes for organic solvent nanofiltration. Gr. Chem. 2014, 16, 1383-1392. [CrossRef]

104. Xing, D.Y.; Chan, S.Y.; Chung, T.S. Molecular interactions between polybenzimidazole and [EMIM]OAc, and derived ultrafiltration membranes for protein separation. Gr. Chem. 2012, 14, 1405-1412. [CrossRef] 
105. Xing, D.Y.; Peng, N.; Chung, T.-S. Formation of cellulose acetate membranes via phase inversion using ionic liquid, [BMIM]SCN, as the solvent. Ind. Eng. Chem. Res. 2010, 49, 8761-8769. [CrossRef]

106. Livazovic, S.; Li, Z.; Behzad, A.R.; Peinemann, K.V.; Nunes, S.P. Cellulose multilayer membranes manufacture with ionic liquid. J. Membr. Sci. 2015, 490, 282-293. [CrossRef]

107. Falca, G.; Musteata, V.E.; Behzad, A.R.; Chisca, S.; Nunes, S.P. Cellulose hollow fibers for organic resistant nanofiltration. J. Membr. Sci. 2019, 586, 151-161. [CrossRef]

108. Kim, D.; Livazovic, S.; Falca, G.; Nunes, S.P. Oil-water separation using membranes manufactured from cellulose/ionic liquid solutions. ACS Sustain. Chem. Eng. 2019, 7, 5649-5659. [CrossRef]

109. Esfahani, M.R.; Taylor, A.; Serwinowski, N.; Parkerson, Z.J.; Confer, M.P.; Kammakakam, I.; Bara, J.E.; Esfahani, A.R.; Mahmoodi, S.N.; Koutahzadeh, N.; et al. Sustainable Novel Bamboo-Based Membranes for Water Treatment Fabricated by Regeneration of Bamboo Waste Fibers. ACS Sustain. Chem. Eng. 2020, 8, 4225-4235. [CrossRef]

110. Rajabzadeh, S.; Maruyama, T.; Sotani, T.; Matsuyama, H. Preparation of PVDF hollow fiber membrane from a ternary polymer/solvent/nonsolvent system via thermally induced phase separation (TIPS) method. Sep. Purif. Technol. 2008, 63, 415-423. [CrossRef]

111. Hassankiadeh, N.T.; Cui, Z.; Kim, J.H.; Shin, D.W.; Lee, S.Y.; Sanguineti, A.; Arcella, V.; Lee, Y.M.; Drioli, E. Microporous poly(vinylidene fluoride) hollow fiber membranes fabricated with PolarClean as water-soluble green diluent and additives. $J$. Membr. Sci. 2015, 479, 204-212. [CrossRef]

112. Wang, H.H.; Jung, J.T.; Kim, J.F.; Kim, S.; Drioli, E.; Lee, Y.M. A novel green solvent alternative for polymeric membrane preparation via nonsolvent-induced phase separation (NIPS). J. Membr. Sci. 2019, 574, 44-54. [CrossRef]

113. Marino, T.; Galiano, F.; Molino, A.; Figoli, A. New frontiers in sustainable membrane preparation: Cyrene ${ }^{\mathrm{TM}}$ as green bioderived solvent. J. Membr. Sci. 2019, 580, 224-234. [CrossRef]

114. Hailemariam, R.H.; Woo, Y.C.; Damtie, M.M.; Kim, B.C.; Park, K.-D.; Choi, J.-S. Reverse osmosis membrane fabrication and modification technologies and future trends: A review. Adv. Colloid Interface Sci. 2020, 276, 102100. [CrossRef]

115. Lau, W.J.; Ismail, A.; Misdan, N.; Kassim, M. A recent progress in thin film composite membrane: A review. Desalination 2011, 287, 190-199. [CrossRef]

116. Xu, W.; Chen, Q.; Ge, Q. Recent advances in forward osmosis (FO) membrane: Chemical modifications on membranes for FO processes. Desalination 2017, 419, 101-116. [CrossRef]

117. Otitoju, T.A.; Saari, R.A.; Ahmad, A.L. Progress in the modification of reverse osmosis (RO) membranes for enhanced performance. J. Ind. Eng. Chem. 2018, 67, 52-71. [CrossRef]

118. Park, H.M.; Yoo, J.; Lee, Y.T. Improved fouling resistance for RO membranes by a surface modification method. J. Ind. Eng. Chem. 2019, 76, 344-354. [CrossRef]

119. Kolb, H.C.; Finn, M.G.; Sharpless, K.B. Click chemistry: Diverse chemical function from a few good reactions. Angew. Chem. Int. Ed. 2001, 40, 2004-2021. [CrossRef]

120. Wang, C.; Ikhlef, D.; Kahlal, S.; Saillard, J.Y.; Astruc, D. Metal-catalyzed azide-alkyne "click" reactions: Mechanistic overview and recent trends. Coord. Chem. Rev. 2016, 316, 1-20. [CrossRef]

121. Kolb, H.C.; Sharpless, K.B. The growing impact of click chemistry on drug discovery. Drug Discov. Today 2003, 8, $1128-1137$. [CrossRef]

122. Rostovtsev, V.V.; Green, L.G.; Fokin, V.V.; Sharpless, K.B. A Stepwise huisgen cycloaddition process: Copper(I)-catalyzed regioselective "ligation" of azides and terminal alkynes. Angew. Chem. Int. Ed. 2002, 41, 2596-2599. [CrossRef]

123. Tornøe, C.W.; Christensen, C.; Meldal, M. Peptidotriazoles on solid phase: [1,2,3]-triazoles by regiospecific Copper(I)-catalyzed 1,3-dipolar cycloadditions of terminal alkynes to azides. J. Org. Chem. 2002, 67, 3057-3064. [CrossRef] [PubMed]

124. Hou, X.; Ke, C.; Fraser Stoddart, J. Cooperative capture synthesis: Yet another playground for copper-free click chemistry. Chem. Soc. Rev. 2016, 45, 3766-3780. [CrossRef] [PubMed]

125. He, Y.; Hoi, H.; Montemagno, C.D.; Abraham, S. Functionalized polymeric membrane with aquaporin using click chemistry for water purification application. J. Appl. Polym. Sci. 2018, 135, 46678. [CrossRef]

126. Yang, Y.; Ramos, T.L.; Heo, J.; Green, M.D. Zwitterionic poly(arylene ether sulfone) copolymer/poly(arylene ether sulfone) blends for fouling-resistant desalination membranes. J. Membr. Sci. 2018, 561, 69-78. [CrossRef]

127. Wang, C.; Such, G.K.; Widjaya, A.; Lomas, H.; Stevens, G.; Caruso, F.; Kentish, S.E. Click poly(ethylene glycol) multilayers on RO membranes: Fouling reduction and membrane characterization. J. Membr. Sci. 2012, 409, 9-15. [CrossRef]

128. Haldón, E.; Nicasio, M.C.; Pérez, P.J. Copper-catalysed azide-alkyne cycloadditions (CuAAC): An update. Org. Biomol. Chem. 2015, 13, 9528-9550. [CrossRef]

129. Zhang, G.; Yan, H.; Ji, S.; Liu, Z. Self-assembly of polyelectrolyte multilayer pervaporation membranes by a dynamic layer-by-layer technique on a hydrolyzed polyacrylonitrile ultrafiltration membrane. J. Membr. Sci. 2007, 292, 1-8. [CrossRef]

130. Cho, K.L.; Lomas, H.; Hill, A.J.; Caruso, F.; Kentish, S.E. Spray assembled, cross-linked polyelectrolyte multilayer membranes for salt removal. Langmuir 2014, 30, 8784-8790. [CrossRef]

131. Wang, L.; Wang, N.; Zhang, G.; Ji, S. Covalent Crosslinked assembly of tubular ceramic-based multilayer nanofiltration membranes for dye desalination. AIChE J. 2013, 59, 3834-3842. [CrossRef]

132. Suwaileh, W.A.; Johnson, D.J.; Sarp, S.; Hilal, N. Advances in forward osmosis membranes: Altering the sub-layer structure via recent fabrication and chemical modification approaches. Desalination 2018, 436, 176-201. [CrossRef] 
133. Liang, H.Q.; Hung, W.S.; Yu, H.H.; Hu, C.C.; Lee, K.R.; Lai, J.Y.; Xu, Z.K. Forward osmosis membranes with unprecedented water flux. J. Membr. Sci. 2017, 529, 47-54. [CrossRef]

134. McCutcheon, J.R.; Elimelech, M. Influence of concentrative and dilutive internal concentration polarization on flux behavior in forward osmosis. J. Membr. Sci. 2006, 284, 237-247. [CrossRef]

135. Zhou, J.; He, H.L.; Sun, F.; Su, Y.; Yu, H.Y.; Gu, J.S. Structural parameters reduction in polyamide forward osmosis membranes via click modification of the polysulfone support. Colloids Surf. A Physicochem. Eng. Asp. 2020, 585, 124082. [CrossRef]

136. Soroush, A.; Ma, W.; Silvino, Y.; Rahaman, M.S. Surface modification of thin film composite forward osmosis membrane by silver-decorated graphene-oxide nanosheets. Environ. Sci. Nano 2015, 2, 395-405. [CrossRef]

137. Yu, H.Y.; Kang, Y.; Liu, Y.; Mi, B. Grafting polyzwitterions onto polyamide by click chemistry and nucleophilic substitution on nitrogen: A novel approach to enhance membrane fouling resistance. J. Membr. Sci. 2014, 449, 50-57. [CrossRef]

138. Carlsson, J.O.; Martin, P.M. Chapter 7-Chemical Vapor Deposition. In Handbook of Deposition Technologies for Films and Coatings, 3rd ed.; Martin, P.M., Ed.; William Andrew Publishing: Norwich, NY, USA, 2010; pp. 314-363. [CrossRef]

139. Makhlouf, A.S.H. 1-Current and advanced coating technologies for industrial applications. In Nanocoatings and Ultra-Thin Films; Makhlouf, A.S.H., Tiginyanu, I., Eds.; Woodhead Publishing: Swaston/Cambridge, UK, 2011; pp. 3-23. [CrossRef]

140. Okada, K. Plasma-enhanced chemical vapor deposition of nanocrystalline diamond. Sci. Technol. Adv. Mater. 2007, 8, 624-634. [CrossRef]

141. Katz, A.; Lee, C.H.; Tai, K.L. Advanced metallization schemes for bonding of InP-based laser devices to CVD-diamond heatsinks. Mater. Chem. Phys. 1994, 37, 303-328. [CrossRef]

142. O'Brien, P. Chemical Vapor Deposition. In Encyclopedia of Materials: Science and Technology; Buschow, K.H.J., Cahn, R.W., Flemings, M.C., Ilschner, B., Kramer, E.J., Mahajan, S., Veyssière, P., Eds.; Elsevier: Oxford, UK, 2001; pp. 1173-1176.

143. Wang, J.T. Chapter 7-CVD and its related theories in inorganic synthesis and materials preparations. In Modern Inorganic Synthetic Chemistry; Xu, R., Pang, W., Huo, Q., Eds.; Elsevier: Amsterdam, The Netherlands, 2011; pp. 151-171. [CrossRef]

144. You, Y.; Ito, A.; Tu, R.; Goto, T. Preparation of the c-axis oriented aln film by laser chemical vapor deposition using a newly proposed $\mathrm{Al}(\mathrm{Acac}) 3$ porecursor. J. Cryst. Growth 2013, 365, 1-5. [CrossRef]

145. Ozaydin-Ince, G.; Matin, A.; Khan, Z.; Zaidi, S.M.J.; Gleason, K.K. Surface modification of reverse osmosis desalination membranes by thin-film coatings deposited by initiated chemical vapor deposition. Thin Solid Films 2013, 539, 181-187. [CrossRef]

146. Matin, A.; Shafi, H.; Wang, M.; Khan, Z.; Gleason, K.; Rahman, F. Reverse osmosis membranes surface-modified using an initiated chemical vapor deposition technique show resistance to alginate fouling under cross-flow conditions: Filtration \& subsequent characterization. Desalination 2016, 379, 108-117. [CrossRef]

147. Kazemi, A.S.; Abdi, Y.; Eslami, J.; Das, R. Support based novel single layer nanoporous graphene membrane for efficacious water desalination. Desalination 2019, 451, 148-159. [CrossRef]

148. Lai, G.S.; Lau, W.J.; Goh, P.S.; Karaman, M.; Gürsoy, M.; Ismail, A.F. Development of thin film nanocomposite membrane incorporated with plasma enhanced chemical vapor deposition-modified hydrous manganese oxide for nanofiltration process. Compos. Part B Eng. 2019, 176, 107328. [CrossRef]

149. Dowling, D.P. 4.07-Surface processing using cold atmospheric pressure plasmas. In Comprehensive Materials Processing; Hashmi, S., Batalha, G.F., Van Tyne, C.J., Yilbas, B., Eds.; Elsevier: Oxford, UK, 2014; pp. 171-185. [CrossRef]

150. Shi, D.; Lian, J.; He, P.; Wang, L.M.; Xiao, F.; Yang, L.; Schulz, M.J.; Mast, D.B. Plasma coating of carbon nanofibers for enhanced dispersion and interfacial bonding in polymer composites. Appl. Phys. Lett. 2003, 83, 5301-5303. [CrossRef]

151. Kubo, M.; Taguchi, T.; Shimada, M. Preparation of nanoparticle-embedded thin films by simultaneous feeding of gaseous and solid raw materials in plasma-enhanced chemical vapor deposition process. Thin Solid Films 2017, 632, 55-65. [CrossRef]

152. Vandencasteele, N.; Reniers, F. Plasma-modified polymer surfaces: Characterization using XPS. J. Electron Spectrosc. Relat. Phenom. 2010, 178, 394-408. [CrossRef]

153. Yu, S.; Liu, X.; Liu, J.; Wu, D.; Liu, M.; Gao, C. Surface modification of thin-film composite polyamide reverse osmosis membranes with thermo-responsive polymer (TRP) for improved fouling resistance and cleaning efficiency. Sep. Purif. Technol. 2011, 76, 283-291. [CrossRef]

154. Wu, S.; Xing, J.; Zheng, C.; Xu, G.; Zheng, G.; Xu, J. Plasma modification of aromatic polyamide reverse osmosis composite membrane surface. J. Appl. Polym. Sci. 1997, 64, 1923-1926. [CrossRef]

155. Déon, S.; Koubaa, Z.; Korzhova, E.; Airoudj, A.; Fievet, P.; Roucoules, V. Understanding the impact of poly(allylamine) plasma grafting on the filtration performances of a commercial polymeric membrane. Sep. Purif. Technol. 2019, 212, 30-39. [CrossRef]

156. Ohland, A.L.; Salim, V.M.M.; Borges, C.P. Plasma functionalized hydroxyapatite incorporated in membranes for improved performance of osmotic processes. Desalination 2019, 452, 87-93. [CrossRef]

157. Chul Woo, Y.; Chen, Y.; Tijing, L.D.; Phuntsho, S.; He, T.; Choi, J.S.; Kim, S.H.; Kyong Shon, H. CF4 plasma-modified omniphobic electrospun nanofiber membrane for produced water brine treatment by membrane distillation. J. Membr. Sci. 2017, 529, 234-242. [CrossRef] 